\title{
Cell survival signaling in the bovine mammary gland during the transition from lactation to involution
}

\author{
K. Singh, ${ }^{* 1,2}$ I. Vetharaniam, ${ }^{* 1}$ J. M. Dobson, ${ }^{* 3}$ M. Prewitz, ${ }^{* 4}$ K. Oden, ${ }^{* 5}$ R. Murney, ${ }^{*}$ K. M. Swanson, ${ }^{*}$ \\ R. McDonald, ${ }^{*}$ H. V. Henderson, ${ }^{*}$ and K. Stelwagen† \\ ${ }^{*}$ AgResearch Ltd., Ruakura Research Centre, Private Bag 3123, Hamilton 3214, New Zealand \\ †SciLactis Ltd., Waikato Innovation Park, Ruakura Road, Hamilton 3214, New Zealand
}

\section{ABSTRACT}

In dairy cows, mammary gland involution, and thus a decline in milk production, occurs following peak lactation. To examine the cell signaling pathways regulating involution of the mammary gland, signal transducer and activator of transcription factors (STAT5 and 3), suppressors of cytokine signaling (SOCS1-3 and CIS), insulin-like growth factors (IGF1 and 2), and protein kinase B (Akt) were examined. Mammary involution was induced by termination of milking, and alveolar tissue was collected from 52 nonpregnant, primiparous, midlactation Holstein-Friesian cows killed at 0, 6, 12, 18, 24, 36, 72, and $192 \mathrm{~h}$ postmilking. Qualitative immunohistochemistry showed that activated (phosphorylated) STAT5-P was localized in nuclei of mammary epithelial cells at the early time points, with detection levels decreasing by $24 \mathrm{~h}$ postmilking. In contrast, STAT3-P was barely detectable at the early time points, with detection levels increasing following longer postmilking periods. This was supported by Western analysis, which showed a decline in STAT5 and STAT5-P protein levels by $24 \mathrm{~h}$ postmilking, no change in STAT3 levels, and an increase in STAT3-P protein (barely detectable at the early time points) by $72 \mathrm{~h}$ postmilking. Quantitative real-time reverse transcription $\mathrm{PCR}$ analysis showed SOCS1 and SOCS3 mRNA increased by 72 $\mathrm{h}$ postmilking compared with $6 \mathrm{~h}$ postmilking. The SOCS2 mRNA remained unchanged across the time series, whereas $C I S$ decreased by $18 \mathrm{~h}$ postmilking and

Received October 12, 2015.

Accepted May 1, 2016.

${ }^{1}$ Corresponding authors: kuljeet.singhparhar@outlook.com (for molecular measures and data analysis) and kumar.vetharaniam@ agresearch.co.nz (for model development and simulation)

${ }^{2}$ Current address: Science Consultancy, Hamilton 3200, New Zealand.

${ }^{3}$ Current address: Carne Technologies Ltd., Private Bag 740, Cambridge 3450, New Zealand.

${ }^{4}$ Current address: Leibniz Institute of Polymer Research, Dresden, Germany.

${ }^{5}$ Current address: ManukaMed Ltd., 10 Bisley Road, Hamilton 3214, New Zealand. remained lower compared with that at $6 \mathrm{~h}$ postmilking until $72 \mathrm{~h}$ postmilking. The IGF1 mRNA increased by $192 \mathrm{~h}$ postmilking, whereas IGF2 mRNA decreased by $18 \mathrm{~h}$ postmilking compared with $6 \mathrm{~h}$ postmilking. The IGFBP 5 mRNA and protein levels of Akt and Akt-P remained unchanged over the time series. These results show that reciprocal activation of STAT5 and STAT3 occurs at the onset of mammary gland involution in the bovine, albeit at a slower rate than in rodents. Mathematical modeling of the pathways indicated that activated STAT3 could block the STAT5 pathway by upregulating SOCS3. The regulation of IGF1-Akt signaling suggests that by $192 \mathrm{~h}$ postmilking in dairy cows, the involution process is still in the reversible phase, with quiescent mammary epithelial cells not yet in the senescent phase.

Key words: dairy cow, mammary gland involution, cell survival, signal transducer and activator of transcription factors

\section{INTRODUCTION}

Mammary function and survival of mammary epithelial cells (MEC) are not only regulated at the hormonal level (Wilde et al., 1999) but also locally, as responses to the cessation of milk removal demonstrate that intramammary signals play a role in initiating apoptosis of MEC and involution in both rodents (Quarrie et al., 1996; Travers et al., 1996; Li et al., 1997) and ruminants (Quarrie et al., 1994; Wilde et al., 1997). However, involution of the mammary gland is more gradual in the bovine (Holst et al., 1987; Hurley, 1989; Capuco and Akers, 1999) than in rodents. Many alveolar structures are retained (Holst et al., 1987; Hurley, 1989), which may allow for reversibility of involution following extended nonmilking periods in cows (Noble and Hurley, 1999). Furthermore, the increase in apoptosis of MEC following the cessation of milk removal (Wilde et al., 1997; Singh et al., 2005) does not occur to the same extent in the bovine as in rodent mammary glands.

In rodents, mammary gland involution occurs in 2 stages (Lund et al., 1996), with the first stage being 
reversible up to $48 \mathrm{~h}$ after pup removal, and the second stage (irreversible from $72 \mathrm{~h}$ ) being indicated by loss of the majority of MEC by apoptosis (Walker et al., 1989) and extensive restructuring of the gland to a virgin-like state (Jaggi et al., 1996; Lund et al., 1996; Li et al., 1997). The molecular mechanisms regulating MEC apoptosis have been well studied in rodent mammary gland involution. Serine/threonine kinase Akt is a key cell survival factor (Schwertfeger et al., 2001) with multiple intracellular signaling pathways, either up- or downregulated at the onset of mammary gland involution, mediated through the phosphatidylinositol3-kinase-Akt axis (Baxter et al., 2007). Those that are downregulated include prolactin (PRL) signaling via the inactivation of signal transducer and activator of transcription (STAT)5 (Schmitt-Ney et al., 1992; Liu et al., 1996), insulin-like growth factor (IGF) signaling via the upregulation of IGF-binding protein (IGFBP)5 (Tonner et al., 1997), and the disruption of cell-extracellular matrix interactions via integrins and the downregulation of focal adhesion kinase (Gilmore et al., 2000; McMahon et al., 2004). In contrast, cell death signaling pathways (Clarkson et al., 2000; Nguyen and Pollard, 2000; Baxter et al., 2006) and immune signaling pathways are activated, including leukemia inhibitory factor-signal transducer (LIF), which activates proapoptotic STAT3 (Chapman et al., 1999; Kritikou et al., 2003). The STAT3 activates acute phase response and inflammation related genes (Clarkson et al., 2004) and also IGFBP5, thus providing a link of STAT3 to IGF and Akt survival signaling (Chapman et al., 1999).

The balance between STAT5 and STAT3 signaling plays a role in regulating the transition from lactation to involution. Activation of STAT5 is a survival signal in MEC, suppressing STAT3-mediated apoptosis (Clarkson et al., 2006). Furthermore, LIF negatively modulates STAT5 activation (Granillo et al., 2007). However, the interaction of these STAT signaling pathways at the onset of involution is unclear, although it may be mediated by suppressor of cytokine signaling 3 (SOCS3). Activated STAT3 upregulates SOCS3 (Alexander and Hilton, 2004; Clarkson et al., 2006), which then regulates further STAT3 activation to ensure controlled apoptosis of MEC and mammary tissue remodeling during involution (Sutherland et al., 2006; Robinson et al., 2007). In vitro studies show that SOCS3 can inhibit PRL induction of milk protein gene expression and STAT5 activation, through direct interaction with PRL receptors (PRLR; Dif et al., 2001). Other members of the SOCS family may be more important in the developing mammary gland, such as cytokine inducible SH-2 domain protein (CIS; Tonko-Geymayer et al., 2002), SOCS1 (Lindeman et al., 2001), and SOCS2 (Harris et al., 2006).
The aim of this study was to examine the molecular mechanisms regulating the onset of involution of the bovine mammary gland by investigating the temporal changes in cell survival and death signaling factors and to use mathematical modeling to investigate whether reciprocal patterns of expression between activated STAT5 and STAT3 could arise from cross talk mediated by SOCS3. Such knowledge would provide a greater understanding of the molecular mechanisms that regulate the transition from lactation to involution in the dairy cow. Ultimately, this may inform the development of novel strategies for improving milk production, especially in the later stages of lactation.

\section{MATERIALS AND METHODS}

\section{Animals and Tissue Collection}

All animal manipulations were conducted in compliance with the rules and guidelines of the Ruakura Animal Ethics Committee (Hamilton, New Zealand). Involution of the mammary gland was induced by abrupt termination of milking in 52 nonpregnant primiparous Holstein-Friesian dairy cows at, or close to, their peak milk production in mid lactation $(94 \pm 3$ DIM). The cows were solely pasture-fed, grazing ryegrass/white clover, and were milked twice daily from parturition. Milking was ceased following 2 consecutive 12-h intervals of milking for the designated nonmilking intervals. Before the cessation of milking, the mean daily milk yield was $14.3 \pm 0.3 \mathrm{~kg} / \mathrm{cow}$ and mean SCC in composite (4 quarters) milk was 165,000 $\pm 30,000$ cells $/ \mathrm{ml}$. The experimental design was split across 2 consecutive seasons. In the first season, 42 of the cows (mean $89.1 \pm 2.2 \mathrm{DIM}$ ), balanced for milk yield, were randomly allocated into 0-, 6-, 12-, 18-, 24-, 36-, and 72-h non-milking-interval groups. In the following season, 10 cows (mean 116.9 \pm 6.0 DIM), balanced for milk yield, were randomly allocated into $72-(\mathrm{n}=4)$ and 192-h $(\mathrm{n}=6)$ non-milking-interval groups. Animals were slaughtered (between 1000 and $1100 \mathrm{~h}$ ) at $0,6,12$, $18,24,36,72$, and $192 \mathrm{~h}$ following the last milking, at the Ruakura Abattoir (Hamilton, New Zealand) using standard commercial procedures (electrical stunning followed by exsanguination). Mammary alveolar tissue (approximately $30 \mathrm{~g}$ ) was dissected from the middle of the upper one-third of the gland of a rear quarter of each animal, snap-frozen in liquid nitrogen, and stored at $-80^{\circ} \mathrm{C}$ for subsequent RNA and protein extraction (Singh et al., 2005). Approximately 1.5-cm-thick samples of alveolar tissue $(10 \mathrm{~g})$ were also obtained from each animal, fixed in $4 \%$ phosphate-buffered paraformaldehyde, and processed for histological analysis as previously described (Singh et al., 2005). 


\section{Western Blot Analysis}

Protein was isolated from mammary alveolar tissue in duplicate preparations at the end of the study following collection of the final time point $8 \mathrm{~d}$ postmilking and the concentration determined as described previously (McMahon et al., 2004), with minor modifications. The total homogenate fraction was extracted in $1 \mathrm{~mL}$ of low-salt buffer containing 1\% NP40 detergent and protease inhibitors, and an aliquot was saved for analysis of STAT5, STAT5-P, STAT3, and Akt. The remaining homogenate fraction was centrifuged at $10,000 \times g$ for $30 \mathrm{~min}$ at $4^{\circ} \mathrm{C}$, and the supernatant was collected as the soluble protein fraction for STAT3$\mathrm{P}$ and Akt-P analysis. Twenty micrograms of protein from either fraction was separated by SDS-PAGE using 7.5\% Criterion precast Tris-HCl gels (BioRad, Auckland, New Zealand) and transferred onto nitrocellulose membranes (Hybond-C extra, Amersham Biosciences UK Ltd., Little Chalfont, UK). Duplicate gels were stained with Coomassie blue to indicate uniformity of loading per lane. The membranes were blocked in Trisbuffered saline (TBS) solution $(0.05 \mathrm{M}$ Tris- $\mathrm{HCl}, 0.15$ $M \mathrm{NaCl}, \mathrm{pH}$ 7.6) containing $0.05 \%$ Tween 20 (TBST)$0.1 \%$ BSA and either $1 \%$ polyvinylpyrrolidone- 25 or nonfat milk protein (4 or 10\%) for $2 \mathrm{~h}$. After 3 washes in TBST-BSA, membranes were incubated for $2 \mathrm{~h}$ in TBST-BSA with antibodies targeting STAT5A/B (STAT5, 1:10,000, sc-835), Tyr 694 phosphorylated STAT5A/B (STAT5-P, 1:30,000), STAT3 (1:10,000, sc-482), Tyr 705 phosphorylated STAT3 (STAT3-P, 1:10,000, sc-7993-R), Akt1/2/3 (1:1,000, sc-8312), and Ser 473 phosphorylated Akt1/2/3 (Akt-P, 1:5,000, sc7985-R). The STAT5-P antibody was kindly provided by T. Wheeler (AgResearch Ltd., Hamilton, New Zealand; Wheeler et al., 2001); all other antibodies were from Santa Cruz Biotechnology (Santa Cruz, CA). Following 3 further washes in TBST-BSA, membranes were incubated for $1 \mathrm{~h}$ in TBST-BSA with a 1:10,000 dilution of goat anti-rabbit secondary antibody conjugated to horseradish peroxidase (Sigma-Aldrich Co Ltd., Gillingham, UK) except for STAT5-P, which was incubated in TBST-BSA with 1:15,000 sheep antimouse secondary antibody conjugated to horseradish peroxidase (Silenus Labs Pty Ltd., Boronia, Australia). Finally, membranes were washed in TBST-BSA 3 times and then a further 4 times in TBS. The immunoreactive bands were visualized by enhanced chemiluminescence and then exposed to X-Omat AR film (Carestream Health Inc., Rochester, NY) for 2 to 30 min, depending on the protein of interest. Films were scanned using a densitometer (GS 800, BioRad) and the densities of immunoreactive bands were determined using Quantity One software (BioRad). Protein re-extraction and analysis of samples showed similar phosphorylation patterns, indicating phosphorylation state did not change during storage.

\section{Immunohistochemistry Analysis}

Following dewaxing and rehydration, antigen retrieval and blocking of endogenous peroxidase was conducted as described previously (McMahon et al., 2004). Briefly, avidin and biotin binding sites were blocked for $15 \mathrm{~min}$ each using the Dako premixed kit (Dako Cytomation California Inc., Carpinteria, CA). Any remaining nonspecific binding sites were blocked with normal swine serum (Dako Cytomation, 1:10 dilution in TBST-BSA) for sections to be analyzed for STAT5-P and with horse serum, using the Vectastain Universal ABC Kit (Elite PK-6200, Vector Laboratories Inc., Burlingame, CA) for STAT3-P sections for $2 \mathrm{~h}$. Sections were exposed to primary antibodies (diluted in TBST-BSA-1.5\% normal swine serum or horse serum) overnight at $4^{\circ} \mathrm{C}$. Negative controls were incubated in diluent alone (i.e., no primary antibody) or in rabbit IgG at the same molar concentration as the primary antibody. Sections were rinsed in TBST, exposed to biotinylated universal secondary antibody, for primary antibodies raised in rabbit and mouse (Vectastain Universal ABC Kit, Vector Laboratories) for $1 \mathrm{~h}$ in TBST. Slides were then washed in TBST and subjected to ABC amplification (Vectastain Universal ABC Kit). To visualize positive MEC, slides were developed with 3,3'-diaminobenzidine tetrahydrochloride with additional nickel sulfate to produce a blue-black precipitate and then counterstained in $0.5 \%$ eosin solution. To distinguish between labeled and unlabeled MEC nuclei, slides were stained in nuclear fast red for pink-red nuclei. Location and intensity of STAT5-P and STAT3-P protein signal were examined under $40 \times, 100 \times, 200 \times$, and $400 \times$ magnification using a binocular microscope [Olympus Optical Co. (UK) Ltd., London, UK]. Histological images were photographed using a Prog14 digital camera (Jenoptik GmbH, Jena, Germany) and PaintShopPro software, version 7.02 (Jasc Software Inc., Eden Prairie, MN).

\section{Quantitative Real-Time Reverse-Transcription PCR Analysis}

Total RNA was extracted and purified as described previously (Singh et al., 2005). The RNA integrity was confirmed by denaturing gel electrophoresis and quantified by UV spectrophotometry (Singh et al., 2008). The cDNA was synthesized and mRNA transcripts were quantified by quantitative real-time reverse-transcription-PCR (qRT-PCR) analysis using the relative standard curve method, with SYBR Green master 
mix, in the 7900 Sequence Detection System (Applied Biosystems, Foster City, CA) as described previously (Singh et al., 2005). The primers for STAT5A, STAT3 (Murney et al., 2015), IGF1, IGF2, IGFBP5 (Wall et al., 2005), SOCS1, SOCS2, and SOCS3 (Wall et al., 2006) have been described previously. The housekeeping gene ubiquitin was not differentially expressed across the time series and was used as an internal control (Singh et al., 2008). The PCR products were verified by sequencing (Waikato DNA Sequencing Facility, Hamilton, New Zealand).

\section{Statistical Analysis}

The differences between means were analyzed using REML (GenStat, 2011). For Western blotting analysis, densitometry results were $\log _{10}$-transformed and analyzed using a mixed model with animal, protein preparation, and gel within protein preparation as random effects, and year and time postmilking as fixed effects. For qRT-PCR analysis, the relative mRNA values for each gene were $\log _{10}$-transformed before statistical analysis. For both the Western blotting and qRT-PCR analyses, the data were expressed as back-transformed predicted means at each time point with standard error of the difference (SED) between means. Least significant differences identify the means significantly different from the 6 -h time point $\left({ }^{*} P<0.05,{ }^{* *} P<\right.$ $\left.0.01,{ }^{* * *} P<0.001\right)$. The 6 -h time point was used in preference to the 0 -h time point because $0 \mathrm{~h}$ represents tissue taken after a 12-h milking interval (i.e., the regular milking interval immediately before the start of the experiment was $12 \mathrm{~h}$ ), whereas the 6 -h sample was the sample taken after the shortest milking interval.

\section{Mathematical Modeling}

Two separate mathematical models of the STAT3 and STAT5 signaling pathways were constructed, and these were coupled by a common variable SOCS3 (i.e., blocking receptor activation in the STAT5 pathway and being upregulated by the STAT3 pathway).

This resulted in a model of interacting STAT3 and STAT5 pathways, which is represented in Figure 1. In developing the model, we assumed that the first stage of STAT3 activation involves LIF in equilibrium binding and dissociation to dimerize its receptor (LIFR) with the transmembrane receptor gp130. Similarly, we assumed that the first stage of STAT5 activation involved PRL in equilibrium binding and dissociation to dimerize 2 PRLR. Receptor dimers for both LIF and PRL are phosphorylated by Janus kinase (JAK)2, and in turn phosphorylate the relevant STAT, which in

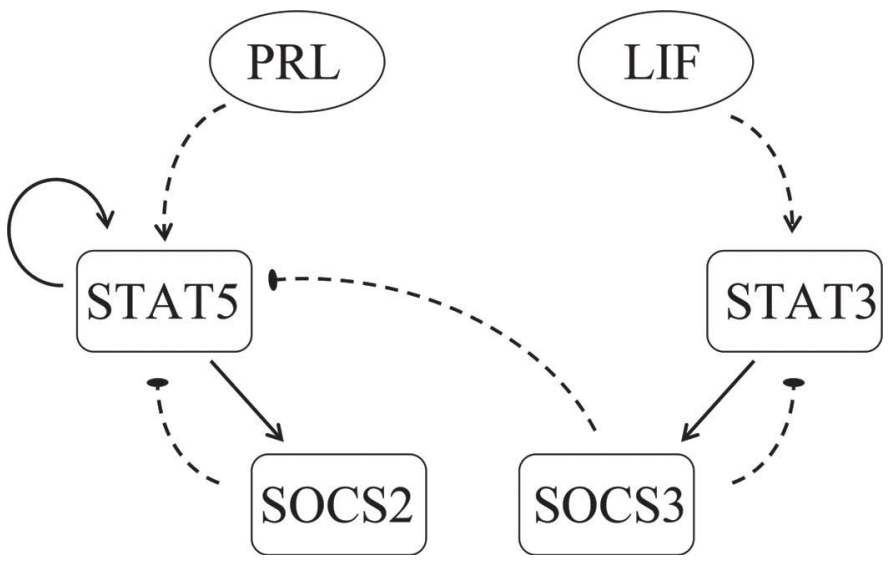

Figure 1. Diagram showing high-level interactions represented in the model. Arrowed dashed lines indicate activation, truncated dashed lines indicate inhibition of activation, solid arrowed lines indicate upregulation. The signal transducer and activator of transcription (STAT) 5 pathway is activated by prolactin (PRL) activity, which upregulates STAT5 protein levels (which feeds forward to strengthen its signal) and suppressor of cytokine signaling (SOCS)2 (which feeds back to control its signal). Activation of the STAT3 pathway by leukemia inhibitory factor (LIF) causes upregulation of SOCS3, which has the dual effect of feedback regulation of STAT3 and attenuation of the STAT5 pathway. The model treats expression of STAT3 as constant (thus assuming it is controlled by factors not included in the model).

addition to other targets, upregulates SOCS proteins which provides negative feedback.

The sub-model of STAT3 signaling was based on a model presented by Davey et al. (2007) but varies in some important respects regarding the mechanisms of STAT3 signaling, which are discussed below. Figure 2A shows the model for STAT3, indicating the important dynamics of STAT3 signaling: LIF (an external input in the model) is in equilibrium binding and dissociation with LIF receptors to form receptor monomers that, in turn, are in equilibrium binding and dissociation with the transmembrane receptor gp130 to form receptor dimers, which are in a flux of being phosphorylated (by recruited JAK2) and dephosphorylated, with the phosphorylated form in turn phosphorylating and activating STAT3. The model represents the effect of activated STAT3 on its target genes to upregulate mRNA for STAT3 and SOCS3 and the translation of the message to produce STAT3 and SOCS3 protein. The model includes terms to represent SOCS3 suppression of STAT3 signaling. Although Davey et al. (2007) modeled SOCS3 binding to the phosphorylated receptor and blocking STAT3 activation, SOCS3 (as with SOCS1) actually prevents phosphorylation of JAK and thus the receptor itself (Kile and Alexander, 2001; Croker et al., 2008). Thus, the latter mechanism was used in the present model and additionally modeled the degradation of the SOCS3-bound complex, which occurs via the ubiquitin 
pathway (Kile and Alexander, 2001). Degradation and internalization of both receptors and phosphorylated and unphosphorylated receptor dimers were represented, as was degradation of mRNA and protein for both SOCS3 and STAT3. Receptor synthesis was assumed to occur at a constant rate, whereas for both SOCS3 and STAT3, Michaelis-Menten (MM) kinetics were used to specify mRNA transcription (as a function of STAT3$\mathrm{P}$ ) and translation (as a function of mRNA). The use of MM kinetics to ensure bounded functions contrasts with the use of linear functions by Davey et al. (2007). An additional constant rate of STAT3 mRNA transcription was included in the model, to ensure that some STAT3 would be present to signal an increase from zero.

Following Davey et al. (2007), we assumed that STAT3 exists in the cytoplasm as preformed dimers before being phosphorylated. Kretzschmar et al. (2004) investigated the existence of predimerized, unphosphorylated STAT3 and could not establish whether this was the case in vivo.

To reduce the number of parameters and variables, the following simplifications were made. Rather than explicitly representing the binding of STAT3 to phosphorylated receptor dimers, phosphorylation and translocation to the nucleus, we assumed that the relative phosphorylation rate of STAT3 dimers arriving in the nucleus was proportional to the abundance of phosphorylated receptor dimers times STAT3 abundance. Additionally, Davey et al. (2007) separately represented the concentrations of factors in the cytoplasm and in the nucleus, whereas, in the present study, concentrations were represented at the cellular level to reflect the resolution of data. The protein inhibitor of activated STAT (PIAS3) was excluded from the model because data indicated that this factor did not vary over time.

The STAT5 sub-model shown in Figure 2B was developed by adapting the STAT3 model and substituting the receptor kinetics from Soboleva et al. (2005), who modeled sequential binding of a ligand to its receptors but used an empirical representation of the JAK/ STAT pathway and did not include STAT and SOCS regulation. The STAT5 sub-model has 2 PRLR binding sequentially to PRL (a constant external input) to form a homodimer, which is subsequently phosphorylated (by JAK2) and then in turn phosphorylates STAT5 dimers. Similar to STAT3 phosphorylation in the LIF sub-model, STAT5 binding to phosphorylated receptor dimers, phosphorylation, and translocation were simplified to assume that the rate of STAT5 dimers appearing in the nucleus is proportional to the abundance of phosphorylated receptor dimers times STAT5 abundance. The STAT5-P then targets genes that encode STAT5 and SOCS2. As with the STAT3 sub-model,
SOCS3 binds to the unphosphorylated receptor dimer (2 PRLR in this case), preventing its phosphorylation. In contrast, SOCS2 binds to the phosphorylated receptor and prevents STAT5 from binding and becoming phosphorylated (Croker et al., 2008) and this was used in the model. The mRNA transcription and translation, receptor synthesis, and degradation of the different proteins and message were all modeled in a similar way to that described for the STAT3 sub-model. There will be a time lag between phosphorylation of STAT and its translocation to the nucleus and the transcription and translation of STAT and SOCS mRNA. These lags are likely to be in the order of hours or less. Writing the model as a set of delay-differential equations to include these lags showed that there was no qualitative difference in model behavior with or without the lags, which was not surprising because the time delays are small in the timeframe of the trial. Thus, delays were ignored in the model, which greatly facilitated ease and speed of computing. The equations for the model are presented in the Appendix.

The RNA and protein assays do not provide actual values but rather relative values, where each measured variable is known only relative to its value at some time point. Although gene expressions may be known relative to a housekeeping gene, there is no relativity between proteins measurements nor between proteins and genes. Thus, it is not possible to determine the model's parameter values from fitting to such data, and it would be misleading to do so. To demonstrate this, consider the linear relationship $y=a x+b$. Estimates for $a$ and $b(\hat{a}$ and $\hat{b})$ can be obtained by the linear regression

$$
y_{i}=\hat{a} x_{i}+\hat{b}+\varepsilon_{i}
$$

where $y_{i}$ are actual values measured at $x_{i}$, where $x$ is the independent variable, and $\varepsilon$ is the error term. Suppose, however, that only relative measurements of $y$ and $x$ are available, and denote these by $w_{i}$ and $z_{i}$, where $w_{i}$ $=s y_{i}$ and $z_{i}=t x_{i}$ for some unknown scaling factors $s$ and $t$. Using these relative values yields the following regression:

$$
w_{i}=\alpha z_{i}+\beta+\eta_{i} \leftrightarrow s y_{i}=\alpha t x_{i}+\beta+\eta_{i},
$$

which yields $\alpha t / s$ and $\beta / s$ as estimates for $a$ and $b$, where the $\alpha, \beta$, and $\eta$ are, respectively, the slope, intercept, and error term. Comparing Equations [1] and [2], it can be seen that the regression with relative values gives estimates that are scaled differently by unknown multipliers. That is, $\alpha \times t=s \times a$ and $\beta=s \times b$. If the actual values for $x$ (i.e., $t=1$ ) are known, the 
A
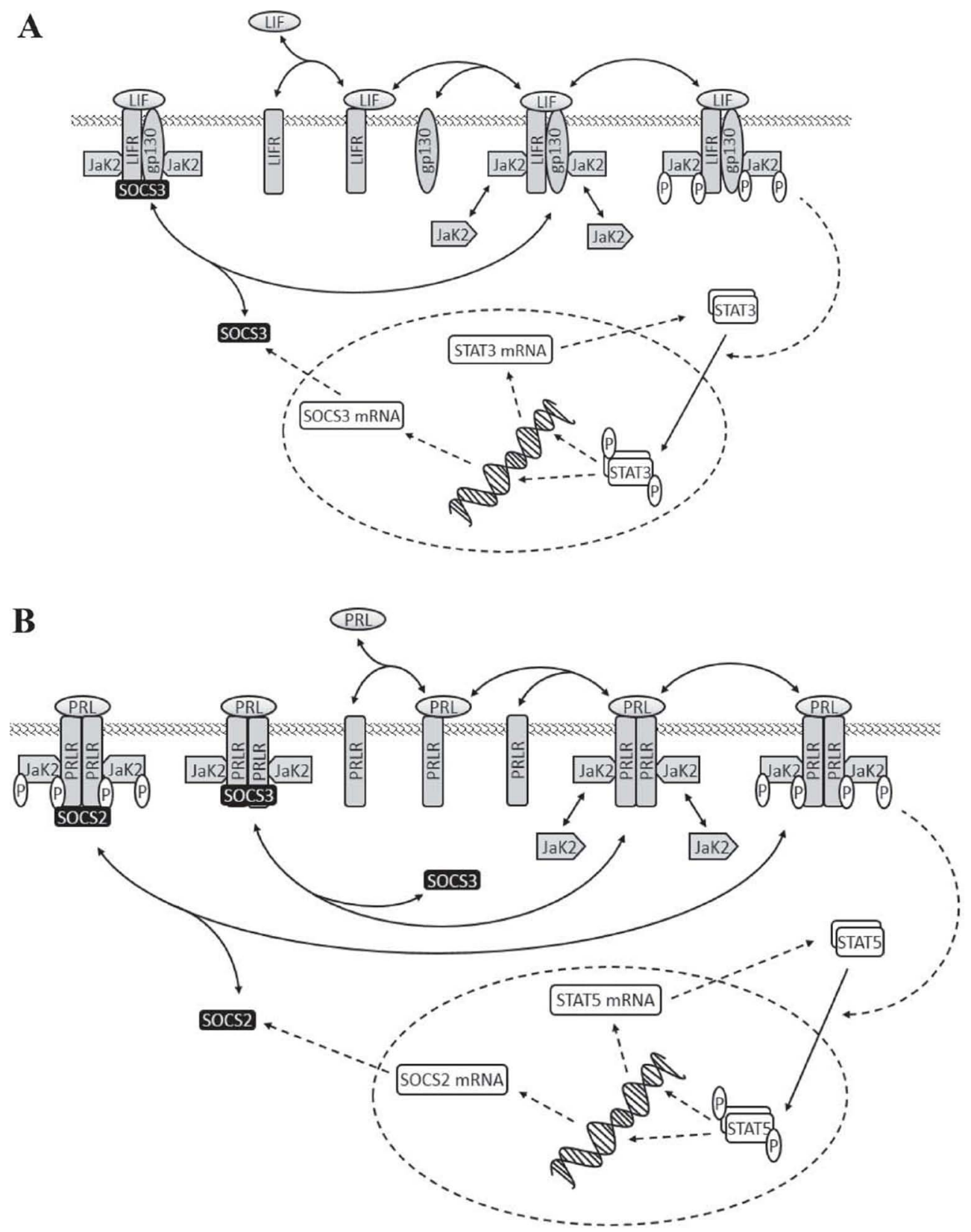

Figure 2. Diagram of JAK (Janus kinase)-STAT (signal transducer and activator of transcription) pathway for STAT3 and STAT5. Solid lines with arrows indicate a transfer of proteins from one state or pool to another, whereas dashed lines with arrows indicate upregulation of a pool or activation of a process. Shapes with letters depict different components of the signaling system: leukemia inhibitory factor (LIF). LIF receptor (LIFR), glycoprotein (gp)130, JAK2, phosphoryl group (P), STAT3, STAT5, suppressor of cytokine signaling (SOCS)2 and SOCS3, prolactin (PRL), prolactin receptor (PRLR). The dotted oval indicates the nucleus, whereas the thin "corrugated" band indicates the cell membrane. (A) Schema for sub-model of STAT3 signaling: LIF is in equilibrium binding and dissociation with LIF receptor to form receptor monomers that are in equilibrium binding and dissociation with gp130 to form receptor dimers which are in a flux of being phosphorylated (by recruited JAK2) and dephosphorylated. The phosphorylated form in turn phosphorylates and activates STAT3, which translocates to the nucleus and targets genes to upregulate mRNA for STAT3 and SOCS3. The STAT3 mRNA is translated to produce more STAT3 protein, providing a positive, feed-forward effect. The SOCS3 mRNA is translated to produce SOCS3 protein, which binds the unphosphorylated receptor dimer, blocking its phosphorylation and thus its ability to activate STAT3, thereby providing a negative feedback. (B) Schema for sub-model of STAT5 signaling: PRL is in equilibrium binding and dissociation with PRL receptors to sequentially form first receptor monomers and then receptor dimers, which are in a flux of being phosphorylated (by recruited JAK2) and dephosphorylated. The phosphorylated form in turn phosphorylates and activates STAT5, which translocates to the nucleus and targets genes to upregulate mRNA for STAT5 and SOCS2. The STAT5 mRNA is translated to produce more STAT5 protein, providing a positive, feedforward effect. The SOCS2 mRNA is translated to produce SOCS2 protein, which binds the phosphorylated receptor dimer, preventing it from phosphorylating STAT5 and thereby providing a negative feedback. Additionally, SOCS3 (produced external to the STAT5 signaling system) binds the unphosphorylated receptor dimer, blocking its phosphorylation and thus its ability to activate STAT5. 
parameter estimates would still contain an unknown multiplier, although their ratio could be estimated. If $x$ and $y$ relative to the same standard are known (i.e., $t=s$ ), then $a$, but not $b$, could be estimated. This limitation on estimating parameters is exacerbated in the model because many of the differential equations (and indeed some of the parameters) have several unknown multipliers due to the relative values of the data, and because data for some variables are not available. Furthermore, numerical integration of the systems of differential equations can convolute more parameters with unknown multipliers in an unspecified way.

For this reason, a formal fit of the model to the data from the trial was not performed because estimates for most parameters would be dubious; instead, we studied aspects of its qualitative behavior pertinent to whether STAT3 activation could downregulate STAT5. Analysis of a model's qualitative behavior is a valid approach in modeling studies (Edelstein-Keshet, 1988; van Riel, 2006; Gunawardena, 2010). In particular, the effect of increasing LIF concentration to activate STAT3 signaling is of interest, as is the response of STAT5-P to different levels of LIF (i.e., to different levels of STAT3-P).

Values for model parameters were largely obtained from the literature, although some parameters were adjusted to give better agreement with the data and others were given nominal values (see Table 1). Solution of the model was performed using the ode15s stiff system solver in Matlab (The Mathworks Inc., Natick, MA). The model was run using a PRL concentration of 0.25 $\mathrm{n} M$ and a LIF concentration of $0 \mathrm{n} M$, until it reached a steady state, which was taken to reflect the average state of a milked cow (Table 2). The effect of drying off; that is, termination of milking (with the last milking at $\mathrm{h}$ 0), was mimicked by increasing LIF concentration after $4 \mathrm{~h}$ to $0.0025 \mathrm{n} M$ by $102 \mathrm{~h}$. This pattern of increase in LIF concentration was found to give good qualitative agreement with the data. Additionally, the LIF concentration was increased in very small increments from 0 to $0.25 \mathrm{n} M$, and model predictions for the steady-state values of STAT3-P and STAT5-P were recorded to develop response curves.

\section{RESULTS}

\section{Localization and Expression of STAT Transcription Factors in Mammary Alveolar During Lactation and Early Involution}

The mRNA levels for STAT5A and STAT3 did not change across the lactation to involution time course (data not shown). However, at the protein level, STAT5A declined by $24 \mathrm{~h}$ postmilking $(P<0.05)$ and was 4.2 -fold $(P<0.001)$ lower at $192 \mathrm{~h}$ than at $6 \mathrm{~h}$ postmilking, whereas STAT5B only declined (2.6-fold) at $192 \mathrm{~h}$ after the last milking relative to $6 \mathrm{~h}(P<0.01$, Figure $3 \mathrm{~A})$. The STAT5-P level declined by $24 \mathrm{~h}$ postmilking $(P<0.001)$ and was 6.6 -fold lower by $192 \mathrm{~h}(P$ $<0.001$ ), compared with that at $6 \mathrm{~h}$ postmilking (Figure $3 \mathrm{~A}, \mathrm{C}$ ). We detected no change in STAT3 protein levels (Figure 3B, D). In contrast, STAT3-P was barely detectable at the early time points and increased by 72 h postmilking ( 3 -fold, $P<0.01)$ and $192 \mathrm{~h}(4.5$-fold, $P$ $<0.01$, Figure 3B, D). Across the time series, STAT5-P had a positive association $(\mathrm{r}=0.83, P<0.001)$ and STAT3-P had a negative association $(\mathrm{r}=-0.58, P<$ 0.001 ) with $\alpha$-LA mRNA levels determined previously by qRT-PCR analysis (Singh et al., 2008).

Figure 4 shows the localization of STAT5-P and STAT3-P of representative samples from 6, 24, and 192 $\mathrm{h}$ postmilking. Both STAT5-P and STAT3-P appeared in the nuclei of MEC. The 6-h time point shows lactating mammary tissue with MEC attached to the basement membrane and surrounding the alveolar lumen. The alveoli were mostly uniform and moderate sized (Figure 4A). By $192 \mathrm{~h}$ postmilking, the representative sample demonstrated characteristics of involuting tissue with moderate to high amounts of large vesicles in the cells (vesicle engorged alveoli), and leukocytes present in alveolar lumen and in areas with large vesicles within the cells (Figure $4 \mathrm{C}$ ). The samples of 6 -h postmilking cows were labeled strongly for STAT5-P protein (Figure $4 \mathrm{~A}, \mathrm{~B})$, with the detection level decreasing by 24 $\mathrm{h}$ postmilking and almost disappearing in the nuclei of MEC from the mammary tissue of cows not milked for 36, 72 (data not shown), and $192 \mathrm{~h}$ (Figure 4C). In contrast, the 6-h samples labeled with STAT3-P showed almost no signal and only nuclear fast red-stained nuclei were detected (Figure 4A). A weak signal was detected for STAT3-P at $24 \mathrm{~h}$ (Figure 4B) but signal intensity was increased following longer postmilking periods with the most intense labeling in 192-h nonmilked tissue (Figure 4C). There was no signal in MEC nuclei for either protein in the negative control samples. Furthermore, no background staining was detected for STAT5-P sections, whereas a little background staining of accumulated milk remained in the alveolar lumen for STAT3-P sections.

\section{Expression of SOCS Family in Mammary Alveolar During Lactation and Early Involution}

The relative mRNA levels of both SOCS1 and SOCS3 were increased by $72 \mathrm{~h}$ postmilking, by $1.9-(P<0.1)$ and 2.3-fold $(P<0.01)$, respectively, and also by 192 h postmilking, by $11-(P<0.001)$ and 4.9 -fold $(P<$ 
0.001), respectively, compared with that at 6 -h postmilking (Figure 5). The relative mRNA levels of SOCS2 remained unchanged across the time series. Relative
mRNA levels of $C I S$ decreased by 2.3 -fold $(P<0.05)$ at $18 \mathrm{~h}$ postmilking compared with the 6 -h time point. The mRNA levels of CIS remained lower compared

Table 1. Values and sources for parameters used in the mathematical model

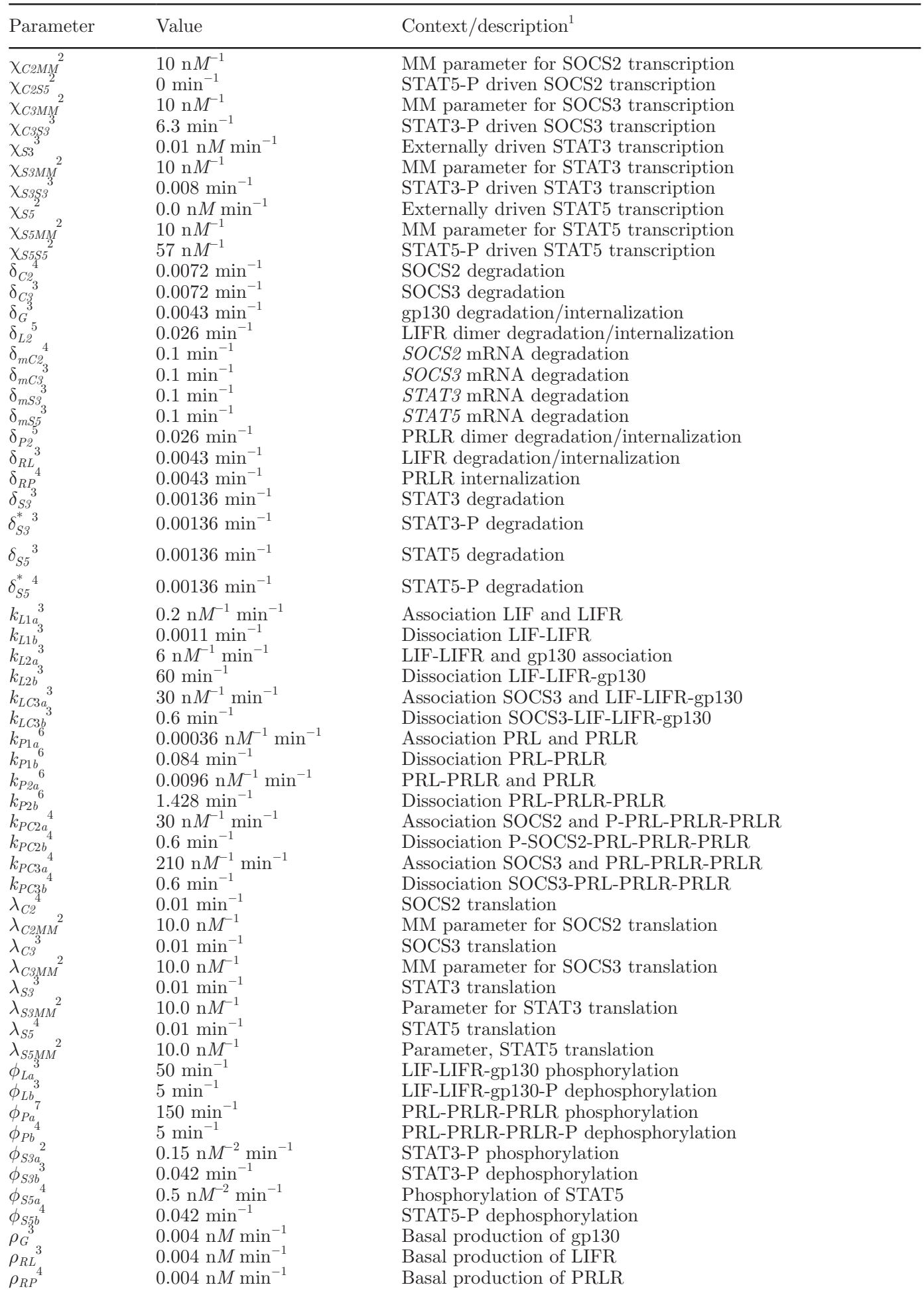


Table 1 (Continued). Values and sources for parameters used in the mathematical model

\begin{tabular}{lcl}
\hline Parameter & Value & Context/description ${ }^{1}$ \\
\hline$u_{L C 3}{ }_{4}$ & $6 \mathrm{~min}^{-1}$ & Ubiquitin degradation of SOCS3-LIF-LIFR-gp130 \\
$u_{P C{ }_{3}}$ & $6 \mathrm{~min}^{-1}$ & Ubiquitin degradation of SOCS2-PRL-PRLR-PRLR \\
$u_{P C 3}$ & $6 \mathrm{~min}^{-1}$ & Ubiquitin of SOCS3-PRL-PRLR-PRLR \\
\hline${ }^{1} \mathrm{MM}=$ Michaelis-Menten; SOCS = suppressor of cytokine signaling; STAT = signal transducer and activator \\
of transcription; gp130 = glycoprotein 130; LIFR = leukemia inhibitory factor (LIF) receptor; PRL = prolac- \\
tin; PRLR = prolactin receptor. \\
${ }^{2}$ Assumed value. \\
${ }^{3}$ Value used by Davey et al. (2007) for corresponding parameter in their LIF model. \\
${ }^{4}$ Parameter value used by Davey et al. (2007) applied to analogous parameter in current model which is not \\
included in the Davey et al. (2007) LIF model. \\
${ }^{5}$ Based on PRL model by Soboleva et al. (2005). \\
${ }^{6}$ From Gertler et al. (1996). \\
${ }^{7}$ Value adjusted manually to obtain better qualitative behavior.
\end{tabular}

with $6 \mathrm{~h}$ until $72 \mathrm{~h}$ postmilking, and they returned to lactating levels by $192 \mathrm{~h}$ postmilking (Figure 5).

\section{Expression of IGF Family in Mammary Alveolar During Lactation and Early Involution}

The relative mRNA levels of IGF1 increased 3 -fold $(P<0.001)$ by $192 \mathrm{~h}$ postmilking compared with 6 $\mathrm{h}$ (Figure 6). The relative mRNA levels of IGF2 were decreased 2.5 -fold $(P<0.05)$ at $18 \mathrm{~h}$ postmilking compared with that at $6 \mathrm{~h}$ postmilking. The relative levels of IGFBP $5 \mathrm{mRNA}$ were not different from $6 \mathrm{~h}$ postmilking at any of the subsequent time points (Figure $5)$.

\section{Akt in Mammary Alveolar During Lactation and Early Involution}

Protein levels of Akt were higher $(P<0.01)$ by almost 1.5-fold immediately following milk removal $(0 \mathrm{~h}$ postmilking) than $6 \mathrm{~h}$ postmilking, whereas the levels were similar to those at $6 \mathrm{~h}$ postmilking for all other

Table 2. Initial (steady-state) values used in the simulations and corresponding to the parameter values in Table 1, when leukemia inhibitory factor (LIF) concentration is zero

\begin{tabular}{lll}
\hline Variable & Initial value & Meaning $^{1}$ \\
\hline$C_{2}$ & $0.0022 \mathrm{n} M$ & SOCS2 concentration \\
$C_{3}$ & $0.0 \mathrm{n} M$ & SOCS3 concentration \\
$G$ & $0.93 \mathrm{n} M$ & gp130 monomer concentration \\
$L_{1}$ & $0.0 \mathrm{n} M$ & LIF-LIFR concentration \\
$L_{2}$ & $0.0 \mathrm{n} M$ & LIF-LIFR-gp130 complex concentration \\
$L_{2}^{*}$ & $0.0 \mathrm{n} M$ & Phosphorylated LIF-LIFR-gp130 concentration \\
$L_{C 3}$ & $0.0 \mathrm{n} M$ & Unphosphorylated LIF-LIFR-gp130-SOCS3 concentration \\
$M_{C 2}$ & $0.0020 \mathrm{n} M$ & SOCS2 mRNA concentration \\
$M_{C 3}$ & $0.0 \mathrm{n} M$ & SOCS3 mRNA concentration \\
$M_{S 3}$ & $0.10 \mathrm{n} M$ & STAT3 mRNA concentration \\
$M_{S 5}$ & $0.21 \mathrm{n} M$ & STAT5 mRNA concentration \\
$P_{1}$ & $0.00093 \mathrm{n} M$ & PRL bound to PRLR concentration \\
$P_{2}$ & $1.9 \times 10^{-6} \mathrm{n} M$ & PRL-PRLR-PRLR concentration \\
$P_{2}^{*}$ & $6.5 \times 10^{-5} \mathrm{n} M$ & Phosphorylated PRL-PRLR-PRLR concentration \\
$P_{C 2}^{*}$ & $6.4 \times 10^{-7} \mathrm{n} M$ & Phosphorylated PRL-PRLR-PRLR-SOCS2 concentration \\
$P_{C 3}$ & $0.0 \mathrm{n} M$ & Unphosphorylated PRL-PRLR-PRLR-SOCS3 concentration \\
$R_{L}$ & $0.93 \mathrm{n} M$ & LIF receptor (LIFR) concentration \\
$R_{P}$ & $0.93 \mathrm{n} M$ & PRL receptor (PRLR) concentration \\
$S_{3}$ & $0.37 \mathrm{n} M$ & STAT3 concentration \\
$S_{3}^{*}$ & $0.0 \mathrm{n} M$ & Phosphorylated STAT3 dimer concentration \\
$S_{5}^{*}$ & $0.50 \mathrm{n} M$ & STAT5 concentration \\
$S_{5}^{*}$ & $3.7 \times 10^{-4} \mathrm{n} M$ & Phosphorylated STAT5 dimer concentration \\
\hline${ }^{1}$ SOCS $=$ suppressor of cytokine signaling; gp130 = glycoprotein 130; LIF = leukemia inhibitory factor; LIFR \\
$=$ LIF receptor; STAT $=\mathrm{signal} \mathrm{transducer} \mathrm{and} \mathrm{activator} \mathrm{of} \mathrm{transcription;} \mathrm{PRL} \mathrm{=} \mathrm{prolactin;} \mathrm{PRLR} \mathrm{=} \mathrm{prolactin}$ \\
receptor. & &
\end{tabular}


time points (Figure 7). The Akt-P levels were similar to those at $6 \mathrm{~h}$ postmilking at all time points (Figure 7 ).

\section{Mathematical Modeling}

Simulation of the trial was performed using the model, and predicted behavior for STAT3 and STAT5 activity and protein are shown in Figure 8. These predictions are in good qualitative agreement with the data from the trial (Figure 3). The model predicted a nonlinear response of STAT5 signaling to STAT3. Rather than STAT5-P decreasing progressively with an

A
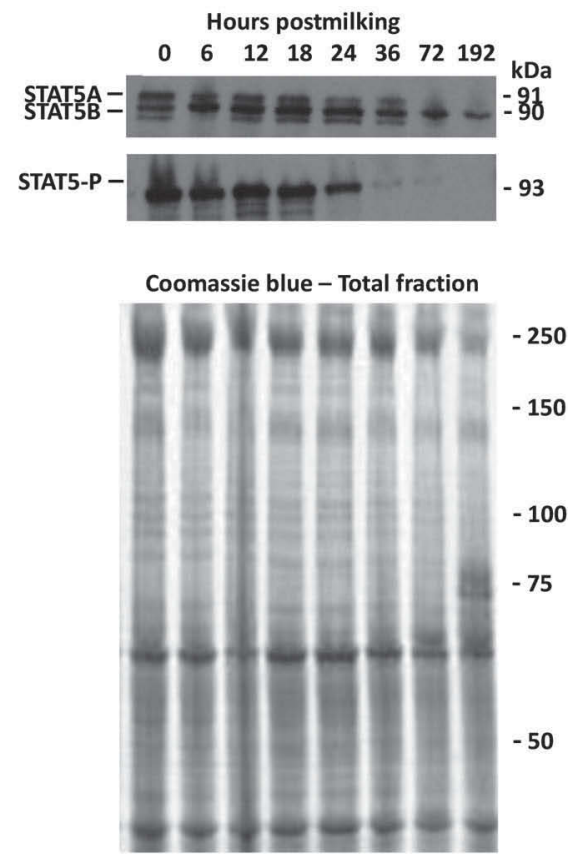

C

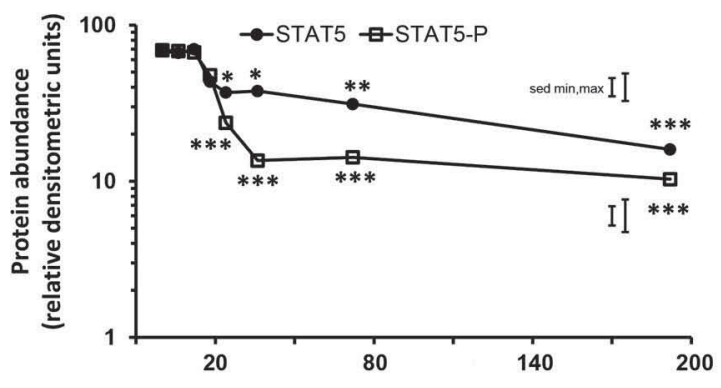

increase in STAT3-P, the model indicated that STAT5 activity would decrease rapidly and be largely attenuated for relatively low levels of STAT3 activity (Figure 8). Predictions for SOCS2 and SOCS3 expression and abundance are shown in Figure 9. The expression of SOCS2 was not predicted to change in the postmilking period, whereas SOCS3 expression was predicted to increase considerably, which is in good qualitative agreement with the data (Figure 5). The increase in STAT3 activation (and hence SOCS3 concentration) was concomitant with the decrease in STAT5 signaling and this, together with the biological data presented

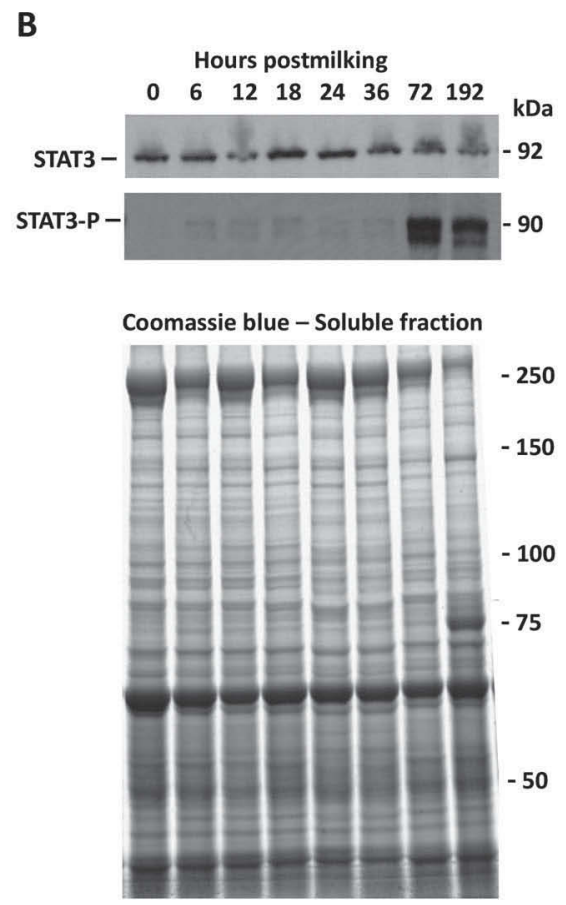

D

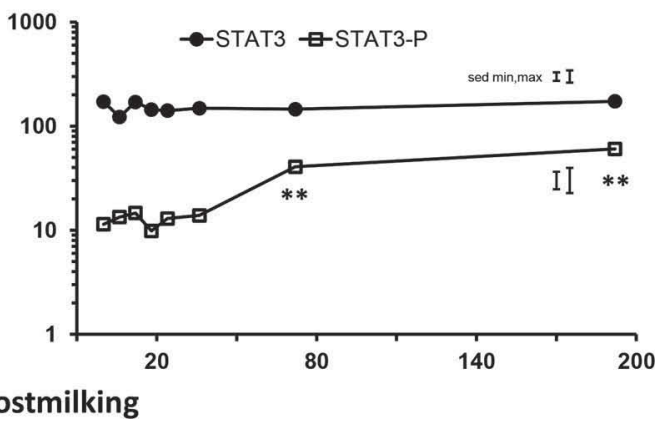

Figure 3. Temporal changes in signal transducer and activator of transcription (STAT)5, STAT5-P, STAT3 and STAT3-P (where P = phosphoryl group) protein levels during the early stages of involution in mammary alveolar tissue induced by abrupt termination of milking in nonpregnant primiparous Friesian dairy cows. Representative Western blots are shown at 0,6,12, 18, 24, 36, 72, and 192 h after the last milking (A, B). Following densitometric analyses, data were expressed as back-transformed mean relative densitometric units with the standard error of the difference (SED) to compare different time points within each protein, and $P$-values $\left(* P<0.05,{ }^{* *} P<0.01,{ }^{* * *} P<0.001\right)$ are relative to the 6 -h time point $(\mathrm{C}, \mathrm{D}) \cdot \min =$ minimum; $\max =$ maximum. Duplicate gels were stained with Coomassie blue to indicate uniformity of loading per lane, and representative examples are shown for the total homogenate (STAT5, STAT5-P, and STAT3) and soluble fractions (STAT3-P). Molecular masses are indicated to the right of the panels. 
above, demonstrates that increased STAT3 activity could provide a mechanism via SOCS3 to attenuate STAT5 signaling in vivo.

The model's prediction that SOCS3 protein abundance would increase is consistent with the predicted increase in SOCS3 expression. However, although
SOCS2 expression was unchanged, SOCS2 abundance increased as SOCS3 expression increased. The mechanism for this may be a decrease in SOCS2 binding to receptor dimers and thus a decrease in SOCS2 lost via ubiquitin degradation. There were no data for SOCS protein abundance from the trial, and the reliability of
STAT5-P
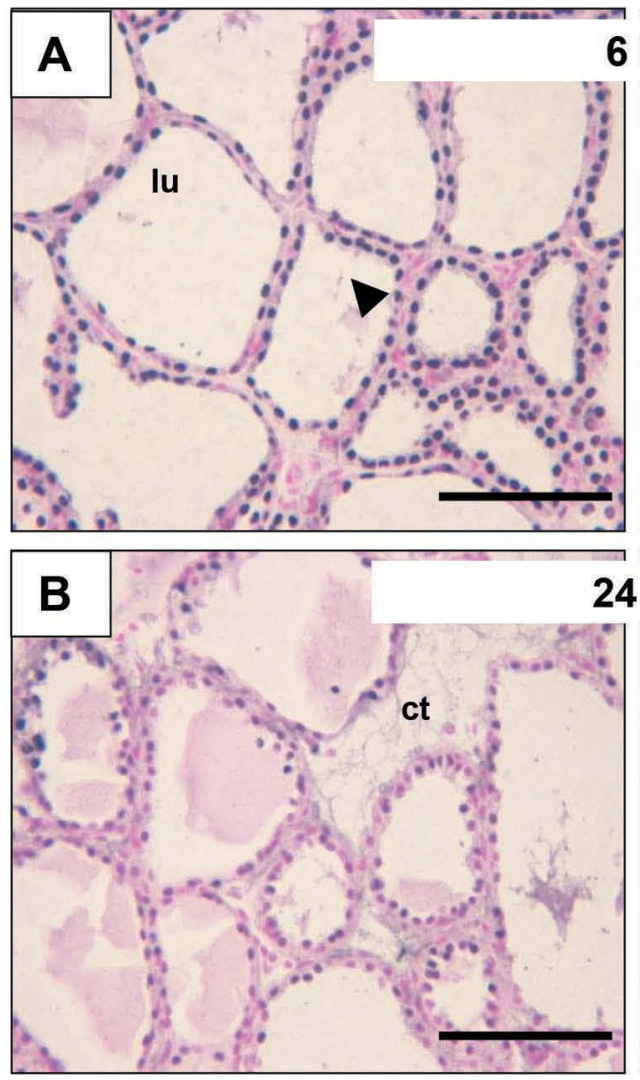

$24 \mathrm{~h}$

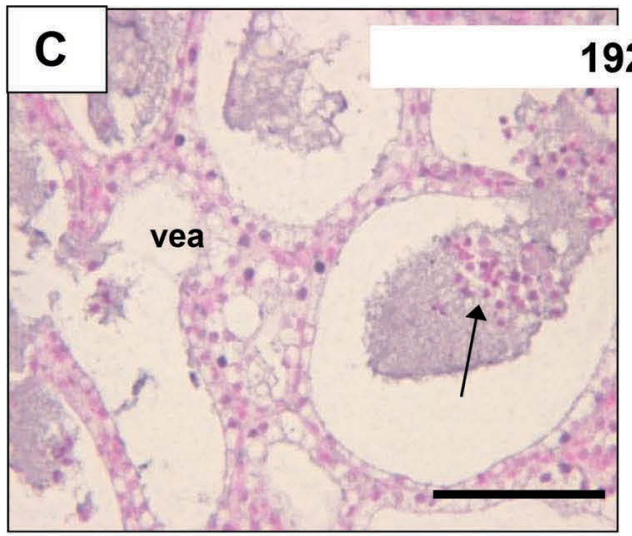

$6 \mathrm{~h}$

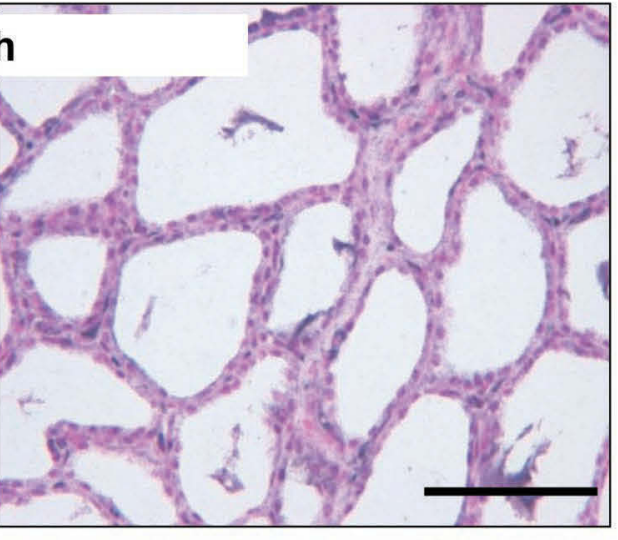

STAT3-P
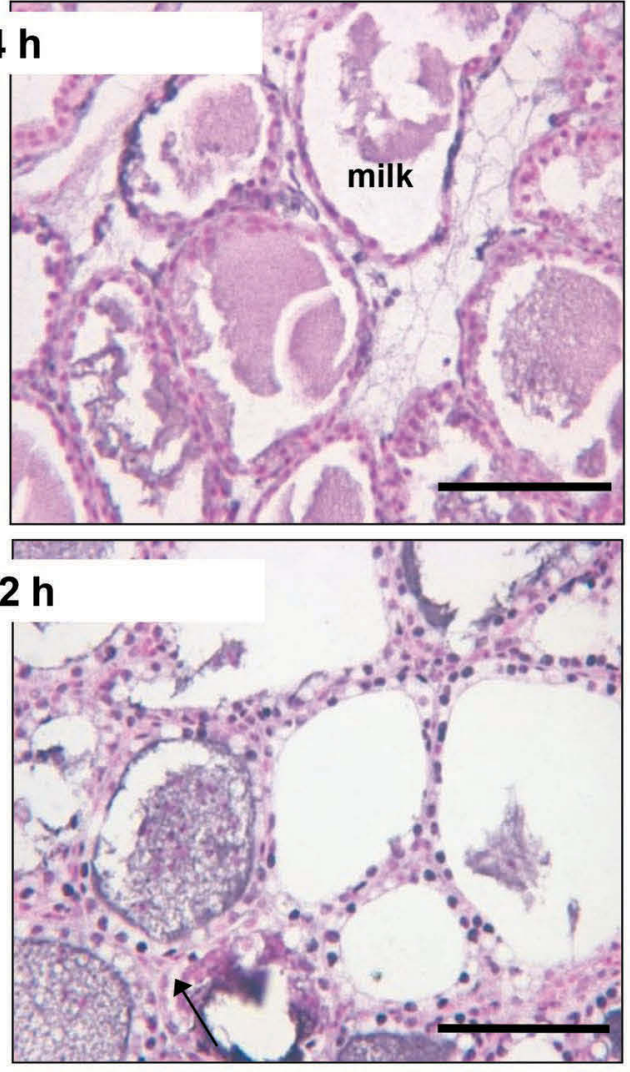
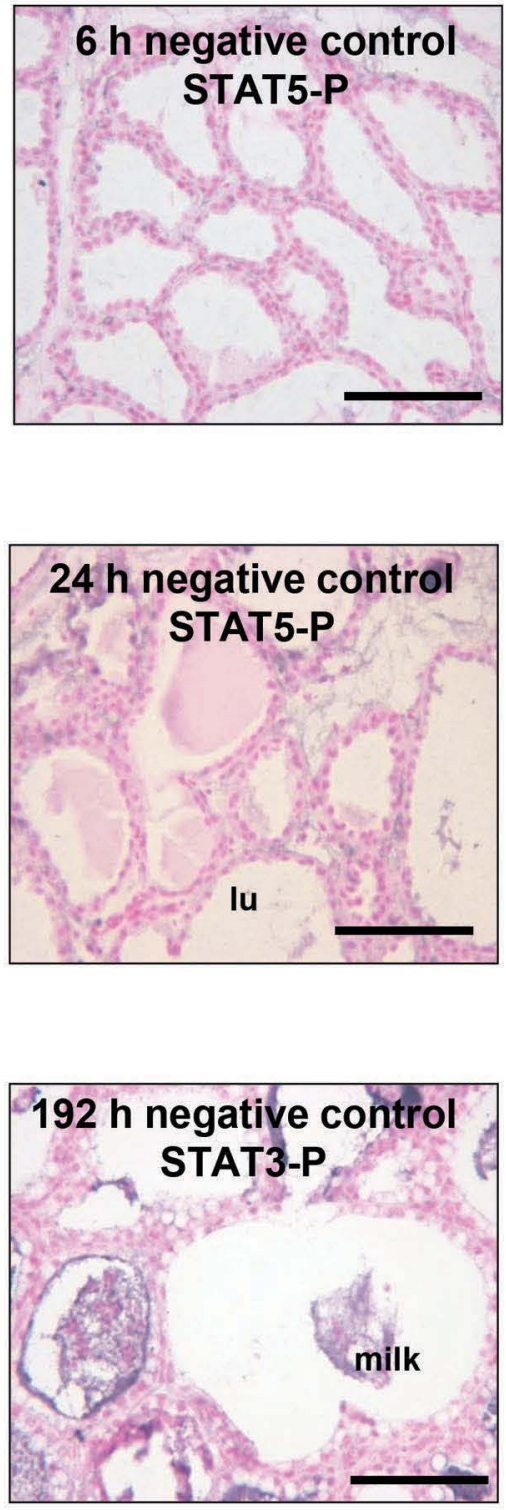

Figure 4. Morphological changes and expression of signal transducer and activator of transcription (STAT)5-P and STAT3-P (where P $=$ phosphoryl group) in bovine alveolar mammary tissue following involution induced by termination of milking at mid lactation. Representative

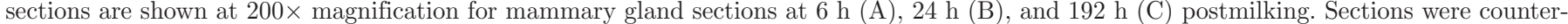
stained either in nuclear fast red (A, B) or eosin (C). Examples of connective tissue (ct), leukocytes (arrows), lumen (lu), milk staining (milk), nuclei (arrowheads) and vesicle engorged alveoli (vea) are shown. Scale bars are $100 \mu \mathrm{m}$. 
this prediction cannot be assessed from this involution trial.

The response of STAT3-P and STAT5-P to LIF concentration showed significantly different behavior, with STAT3-P showing a monotonical increase as LIF increased, whereas STAT5-P declined to a low before increasing toward a plateau (Figure 10). The likely explanation for this is that SOCS3 production appears to become saturated at relatively low levels of LIF and hence levels of STAT3-P (compare Figures 8 and 9), and SOCS3 largely binds to PRLR dimers because LIFR dimers are not abundant. Increasing levels of LIF increase the level of LIFR dimers, which compete for SOCS3 and allow more PRLR dimers to bind and phosphorylate STAT5. Plotting STAT5-P versus STAT3-P for these simulations shows that the system allows at least 3 different states: (1) STAT3 signaling off and STAT5 signaling on; (2) STAT3 signaling on and STAT5 signaling off; (3) STAT3 signaling on and STAT5 signaling on (Figure 11).

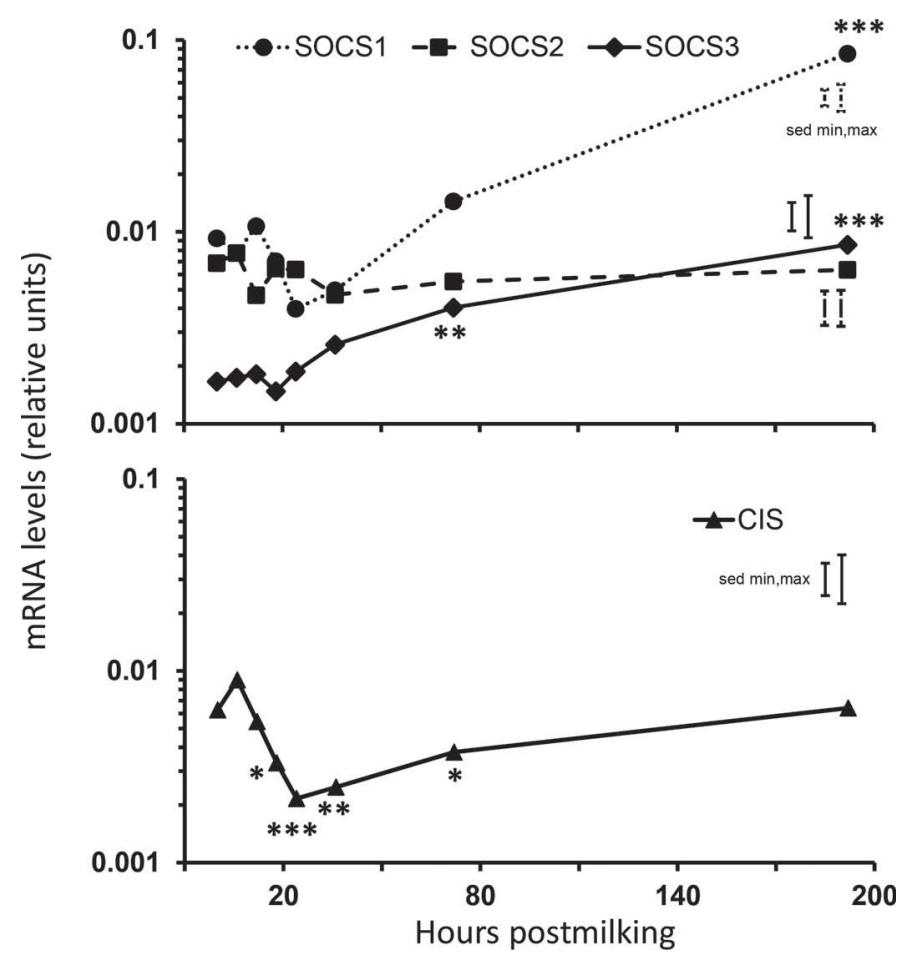

Figure 5. Temporal changes of suppressor of cytokine signaling (SOCS) family, including cytokine inducible $\mathrm{SH}-2$ domain protein (CIS) mRNA levels during the early stages of involution in mammary alveolar tissue induced by abrupt termination of milking in nonpregnant primiparous Friesian dairy cows. $\mathrm{BP}=$ binding protein. Data are expressed as back-transformed mean relative units at each time point with standard error of the difference (SED) between means. min $=$ minimum; $\max =$ maximum. $P$-values $\left({ }^{*} P<0.05\right.$, ${ }^{* *} P<0.01$, ${ }^{* * *} P<$ $0.001)$ are relative to the 6 -h time point for respective genes.

\section{DISCUSSION}

This study showed that at the onset of involution of the bovine mammary gland, STAT5-P declines and STAT3-P increases. Furthermore, mathematical modeling that qualitatively reproduces the biological data indicated that STAT3 can reduce STAT5 signaling by upregulating SOCS3. This supports studies described in rodents that indicate the importance of a balance between these transcription factors for regulating involution of the mammary gland (Clarkson et al., 2006). In agreement with rodent studies (Tonko-Geymayer et al., 2002), CIS was downregulated during early involution and SOCS3 was upregulated. These data support studies that show CIS has a similar developmental pattern of expression to STAT5-P (Liu et al., 1995, 1996) and that activated STAT3 upregulates SOCS3 (Alexander and Hilton, 2004; Clarkson et al., 2006; Sutherland et al., 2006). Furthermore, in the present study, SOCS1 was upregulated and SOCS2 did not change during the transition from lactation to involution. In rodents, SOCS1 and SOCS2 attenuate PRLR-mediated differentiation signals during pregnancy and lactogenesis

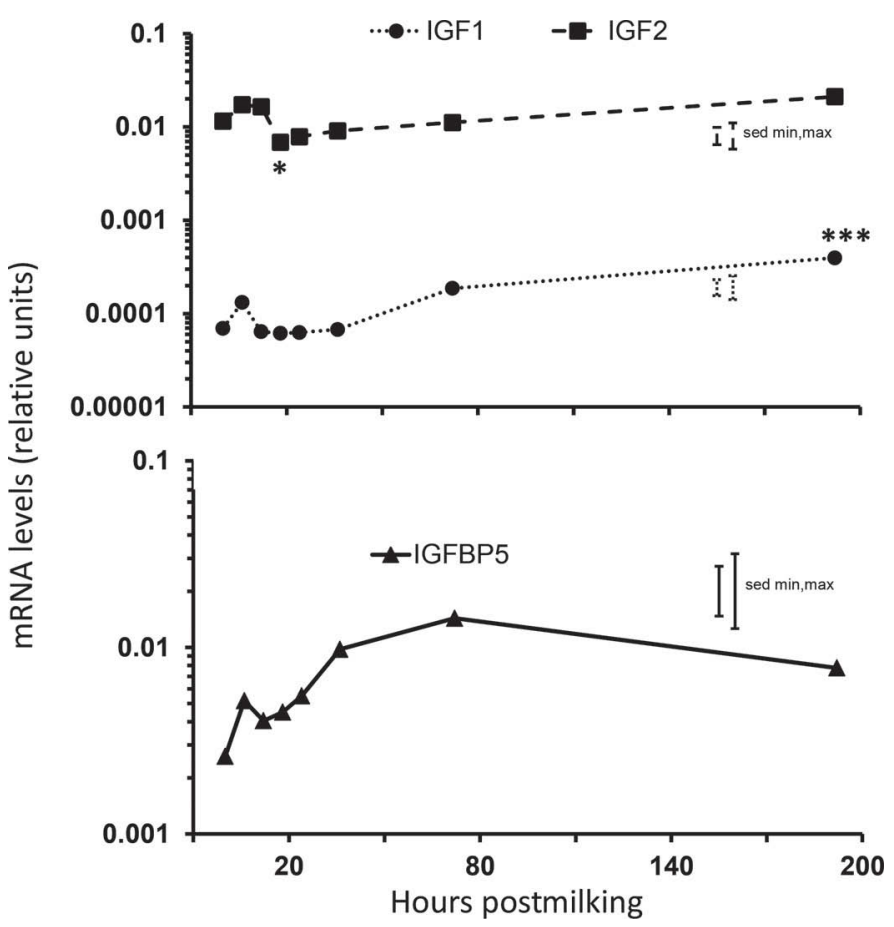

Figure 6. Temporal changes of IGF family mRNA levels during the early stages of involution in mammary alveolar tissue induced by abrupt termination of milking in nonpregnant primiparous Friesian dairy cows. Data are expressed as back-transformed means relative units at each time point with the standard error of the difference (SED) between means. $\min =$ minimum; $\max =$ maximum. $P$-values $\left({ }^{*} P<0.05,{ }^{* * *} P<0.001\right)$ are relative to the 6 -h time point for respective genes. 
(Sutherland et al., 2007). Although SOCS2 is stimulated by STAT5 (Alexander and Hilton, 2004; Clarkson et al., 2006), in the present study, the decline in STAT5-P did not influence SOCS2 mRNA levels, suggesting that SOCS2 does not play a role during bovine mammary gland involution. This agrees with rodent studies that demonstrate SOCS3, but not SOCS2, is capable of inhibiting milk protein gene expression via PRL-STAT5 signaling (Tam et al., 2001). Interestingly, in the present study, SOCS1 expression was increased at the time of STAT3-P upregulation. This supports rodent studies that indicate SOCS1 mRNA is induced by activated STAT3 (Naka et al., 1997). Furthermore, SOCS1 is capable of inhibiting milk protein gene expression (Tam et al., 2001).

The present study showed that expression of $I G F B P 5$, a proapoptotic factor in the mammary gland, remained unchanged and IGF1 expression increased during involution induced at peak lactation. This is in contrast to studies in rodents that demonstrated $I G F B P 5$ expression was increased and IGF1 expression decreased (Tonner et al., 1997; Boutinaud et al., 2004). In agreement with the present study, drying off cows in late lactation increased $I G F 1$ expression; however, in contrast to the present study, IGFBP5 expression was increased (Sorensen et al., 2006). These subtle differences may reflect breed differences or the fact that mammary involution occurred at different stages of the lactation cycle or pregnancy status. For instance, it is postulated that the presence of PRL may repress the expression of IGFBP5 (Accorsi et al., 2002). In support of the lack of change in IGFBP5 expression in the present study, it has been shown that during a 7-d nonmilking period induced in mid lactation for nonpregnant cows, there is no change in circulating PRL levels (Singh et al., 2015), whereas PRL concentrations were lower during the dry period, when cows are pregnant, compared with cows that were still being
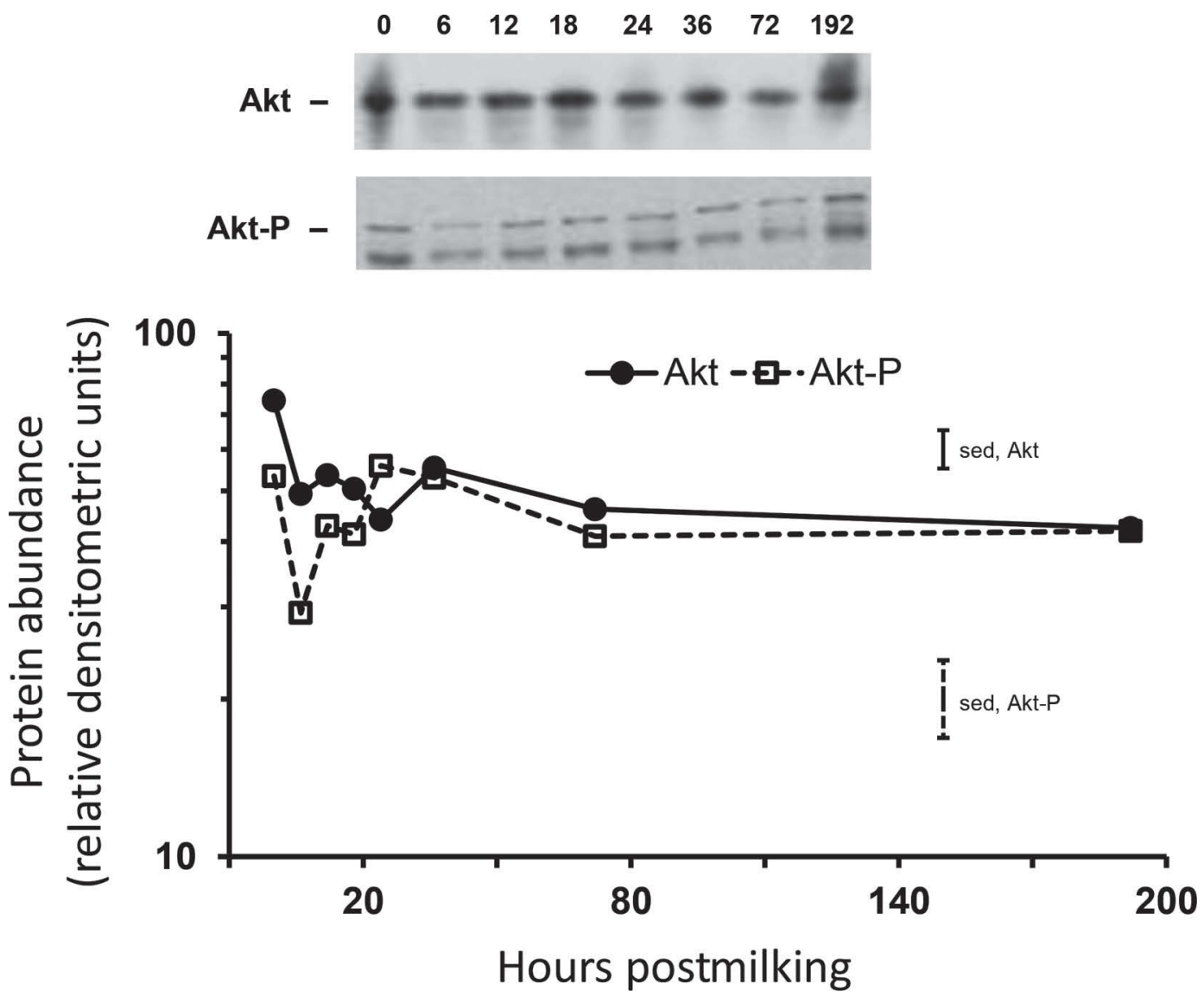

Figure 7. Temporal changes in protein kinase B (Akt)/Akt-P (where $\mathrm{P}=$ phosphoryl group) protein levels during the early stages of involution in mammary alveolar tissue induced by abrupt termination of milking in nonpregnant primiparous Friesian dairy cows. Representative Western blots are shown at $0,6,12,18,24,36,72$, and $192 \mathrm{~h}$ after the last milking. Following densitometric analyses, data are expressed as back-transformed mean relative densitometric units with the standard error of the difference (SED) to compare different time points within each protein. Duplicate gels were stained with Coomassie blue to indicate uniformity of loading per lane and representative examples are shown for the total homogenate (Akt) and soluble fractions (Akt-P, see Figure 3). 

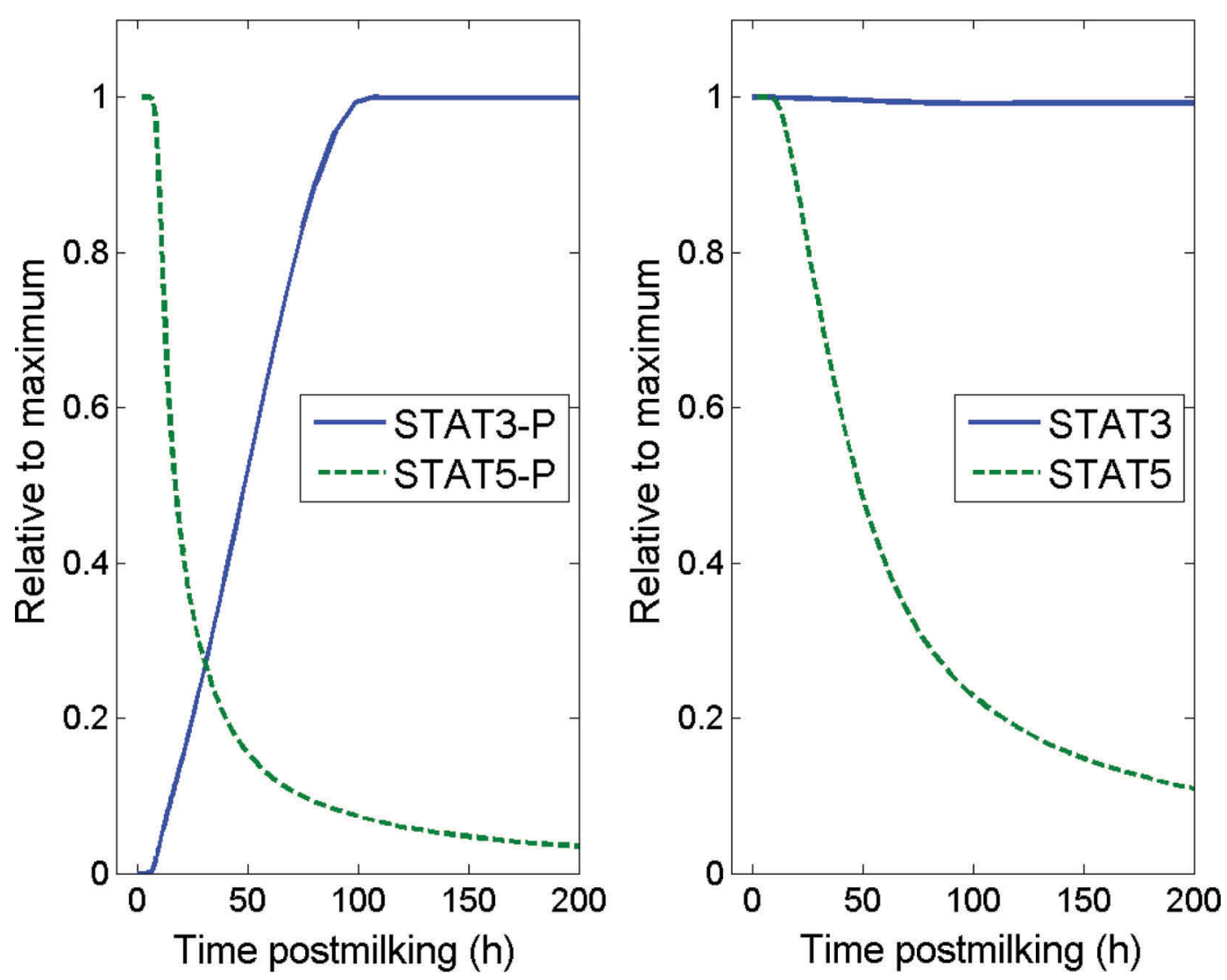

Figure 8. Model predictions for signal transducer and activator of transcription (STAT)5, STAT5-P, STAT3, and STAT3-P (where P = phosphoryl group) protein levels are graphed without scale against time postmilking, showing a stable STAT3 abundance, an increase in STAT3-P, and concomitant decreases in STAT5-P and abundance, all of which are in qualitative agreement with the experimental data. Color version available online.

milked (Bernier-Dodier et al., 2011). This may provide an explanation for the increase in IGFBP5 expression observed following drying-off of pregnant cows at late lactation (Sorensen et al., 2006). Furthermore, in the present study, Akt and Akt-P did not change at the onset of bovine mammary gland involution, which is in contrast to the downregulation observed in rodent studies (Abell et al., 2005; Maroulakou et al., 2008). The IGF1 signal is a survival mechanism for MEC (Flint and Knight, 1997), and the lack of increase in IGFBP5 during involution in the present study suggests that free IGF1 is not sequestered, thus the Akt pathway remains activated and continues to mediate survival signals. These results indicate that when induced at peak lactation, the MEC in regressing alveoli may be quiescent in the early phases of involution and have not progressed to the senescent state. Quiescent alveoli may be capable of reactivation to their active state (Davis et al., 1999; Vetharaniam et al., 2003), which is supported by the observation that at peak lactation, complete recovery of milk yield is achieved when milking of dairy cows is resumed following a nonmilking period of $7 \mathrm{~d}$
(Dalley and Davis, 2006; Singh et al., 2015). In the bovine, the differences in IGF1-Akt signaling, the concurrent increase in proliferation and apoptosis of MEC (Sorensen et al., 2006; Mallah et al., 2013), and the fewer MEC sloughing into the alveolar lumen (Capuco and Akers, 1999), compared with involution of rodent mammary glands, may explain the differences in rate and extent of mammary gland involution that occurs between dairy cows and rodents (Capuco and Akers, 1999; Wilde et al., 1999).

Milk protein gene expression declines more slowly during bovine mammary gland involution (Singh et al., 2008) than that observed in rodents (Travers et al., 1996). However, similar to rodents, the decline begins as early as $24 \mathrm{~h}$ postmilking (Singh et al., 2008), coinciding with the decline in STAT5-P in the present study, which concurs with a role for STAT5 in lactogenesis. In rodents, STAT5 also plays a critical role in survival of MEC (Iavnilovitch et al., 2002; Cui et al., 2004; Clarkson et al., 2006). The PRL signaling has also been associated with enhanced survival of MEC in the bovine (Accorsi et al., 2002; Boutinaud et al., 2012). In bovine 
mammary gland, several other cell survival factors are also downregulated $24 \mathrm{~h}$ postmilking, including integrins, focal adhesion kinase, and anti-apoptotic Bclx (Singh et al., 2005). Although MEC apoptosis increases during involution of the bovine mammary gland (Wilde et al., 1997; Singh et al., 2005; Mallah et al., 2013), the massive cell death of nearly all the alveolar MEC that occurs in rodents during the irreversible phase (Walker et al., 1989) does not occur in the bovine (Wilde et al., 1997; Singh et al., 2005). In the present study, following the downregulation of STAT5-P, upregulation of STAT3-P and SOCS3 occurs $72 \mathrm{~h}$ postmilking, which coincides with the increase in MEC apoptosis (Singh et al., 2005). Thereafter, the increase in IGF1 expression was observed by $192 \mathrm{~h}$ nonmilking in the present study, which concurs with the increase in proliferation during bovine mammary gland involution (Sorensen et al., 2006; Mallah et al., 2013). In contrast, in rodents, the reciprocal changes in STAT5 and STAT3 activation (Philp et al., 1996; Clarkson et al., 2006), increase in SOCS3 (Tonko-Geymayer et al., 2002), and increase in MEC apoptosis (Walker et al., 1989) all occur within
$24 \mathrm{~h}$ of milk stasis; that is, the reversible phase of involution. Furthermore, the increase in apoptotic factors such as Bax also occurs within the reversible phase of involution (Schorr et al., 1999). In bovine mammary glands, Bax is not upregulated until $192 \mathrm{~h}$ postmilking (Singh et al., 2005), suggesting that involution, in the current model, is still in the reversible phase of involution. Taken together, these studies mechanistically support earlier reports that demonstrate remodeling of the mammary gland during involution in ruminants occurs to a lesser extent than in rodents (Capuco and Akers, 1999; Wilde et al., 1999), only replacing senescent or damaged cells (Capuco et al., 2001).

Growth hormone (GH) in addition to PRL may play a role in MEC survival in ruminants (Flint and Knight, 1997). However, this does not affect the outcome of the model, because the signal P (representing PRL concentration) activating STAT5 in the model can be considered as the combined effect of PRL and GH. Although expression of SOCS1 was upregulated along with SOCS3 and may have played a role in blocking STAT5 signaling, the model demonstrated that upregu-
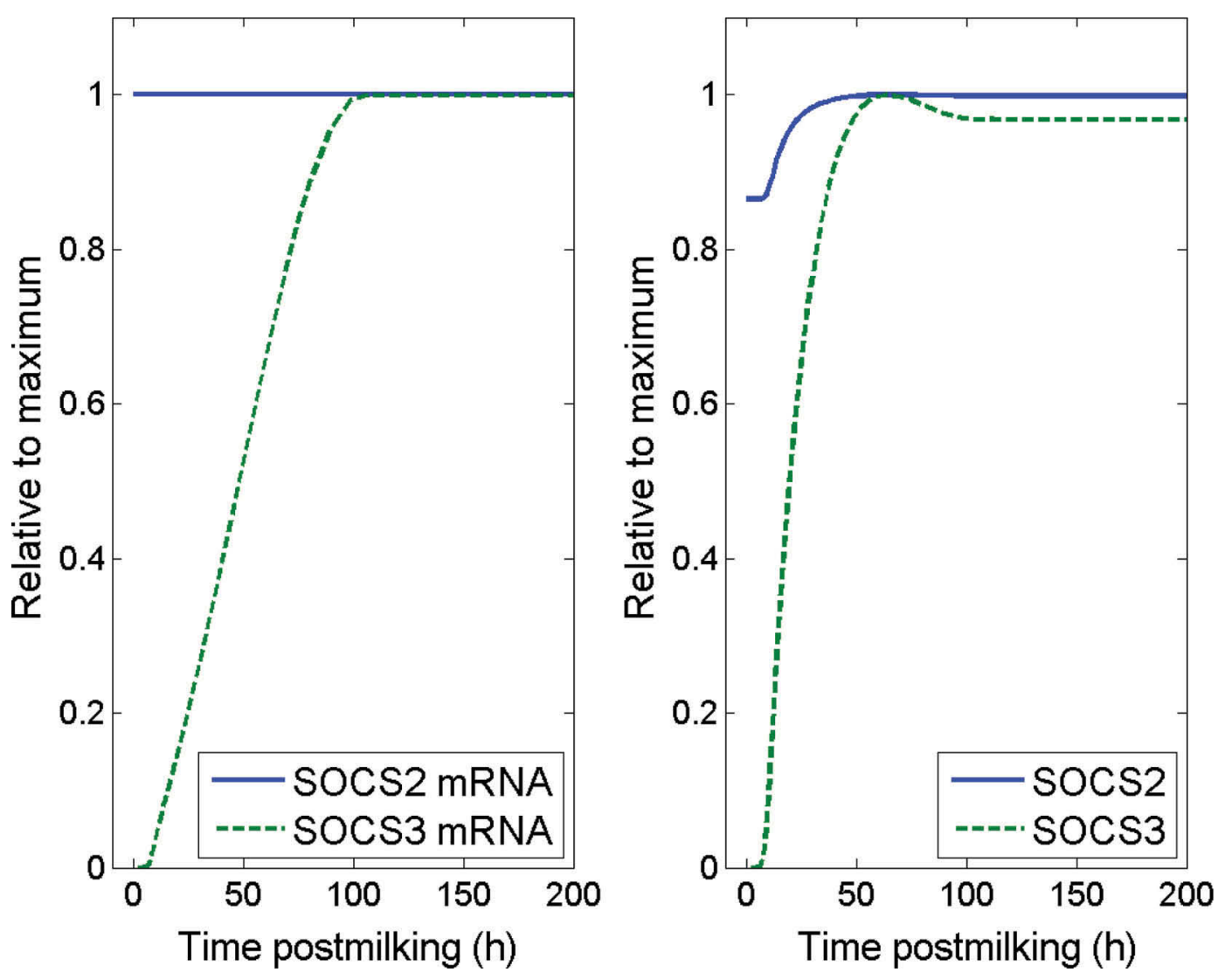

Figure 9. Model predictions for suppressor of cytokine signaling (SOCS) expression and protein are graphed without scale against time postmilking. The model predicted a stable SOCS2 expression and an increase in SOCS3 expression, in agreement with experimental data. The SOCS3 protein was predicted to have a very high increase in abundance, and SOCS2 protein a small increase. Color version available online. 


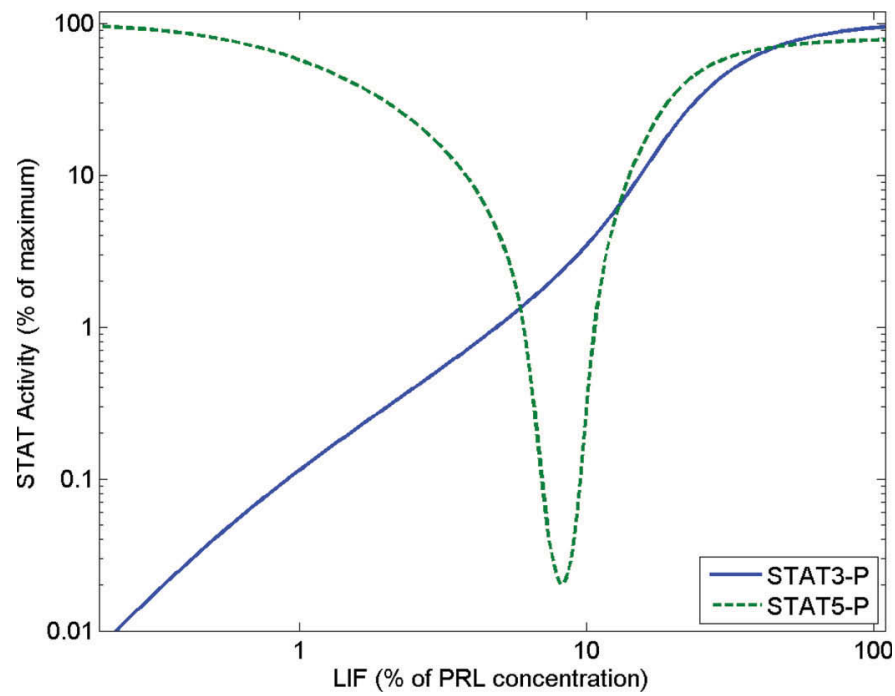

Figure 10. Model predictions for signal transducer and activator of transcription (STAT) 3-P (where $\mathrm{P}=$ phosphoryl group) and STAT5-P levels as leukemia inhibitory factor (LIF) concentrations were increased from 0 to the concentration of prolactin (PRL), expressed as a percentage of their values at zero LIF (omitted on the log scale). The STAT5 activity increased monotonically with LIF concentration whereas STAT5 activity declined to a minimum before recovering to about $80 \%$ of its zero-LIF value. Color version available online.

lation of SOCS3 expression alone was sufficient to block STAT5 signaling. These considerations do not affect the key results of the model, which demonstrated that

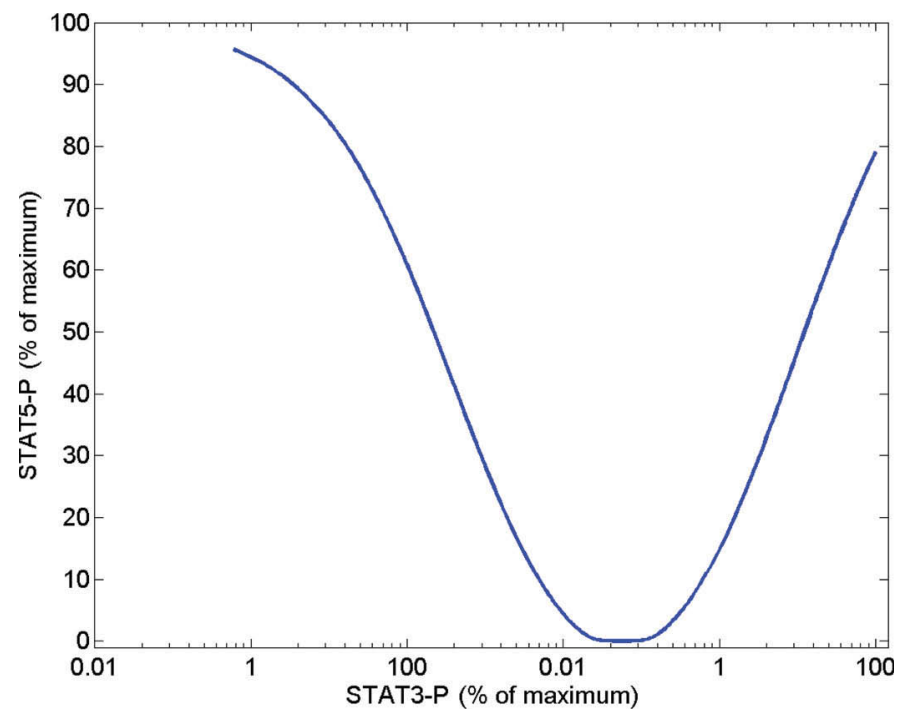

Figure 11. Comparison of model predictions for signal transducer and activator of transcription (STAT) 5 activity for different levels of STAT3 activity. As STAT3 activity increased from 0 (omitted on the log scale), STAT5 activity decreased, reaching a minimum plateau for a region of STAT3 activity, after which it increased with further increases in STAT3-P (where $\mathrm{P}=$ phosphoryl group). Color version available online. activation of STAT3 could indeed reduce STAT5 signaling. However, additional mechanisms may be involved, which would give more precise regulation. Further investigations may elucidate the underlying mechanisms and lead to the development of intervention strategies to ameliorate the effect of diminished STAT5 signaling. This would result in enhanced efficiency of milk production in dairy cows.

The value of this mathematical modeling is that it incorporates known mechanisms for STAT3 and STAT5 signaling, reproduces observed behavior (i.e., downregulation of STAT5 occurring as STAT3 is upregulated), and strongly suggests that STAT3 downregulates STAT5 via SOCS3. Fitting the model to obtain parameter estimates would be purely formulaic and provide no new information. It would not change the outcome that supports SOCS3 as a mechanism by which STAT3 downregulates STAT5, and the values obtained for parameters would not be useful estimates because they would be arbitrarily and unsystematically scaled. The 3 different states of STAT3 and STAT5 activity predicted by the model have biological relevance. The first 2 states, where STAT3 and STAT5 signaling is reciprocally off and on, relate to the experimental observations in this trial. In the third predicted state, STAT5 and STAT3 signaling are both on at the same time and, although this is somewhat surprising and unintuitive, it has in vivo parallels in a pathological case: some tumors exhibit activation of both STAT3 and STAT5 at the same time (Walker et al., 2009). Thus, if the mechanisms modeled in the present study do occur in vivo, the prediction is a powerful result, demonstrating the potential of a mathematical approach to reveal unexpected behavior by exploring the interaction of known mechanisms.

\section{CONCLUSIONS}

This study shows that STAT and SOCS factors play a role during the onset of involution of the bovine mammary gland, as described for rodents, and suggests that the STAT3 signaling is responsible for downregulating STAT5 by upregulating SOCS3, which blocks STAT5 more effectively than it blocks STAT3. However, the regulation of IGF1 and Akt signaling pathways is a major difference between cow and rodent during the switch from lactation to involution at peak lactation. These results indicate that the involution process following $192 \mathrm{~h}$ of nonmilking is still in the reversible phase, with quiescent MEC not yet in the senescent phase compared with rodent involution. Further research is required to fully understand the molecular mechanisms regulating mammary tissue remodeling during involution in the cow. 


\section{ACKNOWLEDGMENTS}

The authors gratefully acknowledge V. Farr, S. Davis, A. Molenaar, T. Wheeler, C. Phyn, and C. McMahon (AgResearch Ltd., Hamilton, New Zealand) for helpful advice and discussions on different aspects of this study. Financial support from the Ministry of Business, Innovation and Employment (MBIE; Wellington, New Zealand) is gratefully acknowledged.

\section{REFERENCES}

Abell, K., A. Bilancio, R. W. Clarkson, P. G. Tiffen, A. I. Altaparmakov, T. G. Burdon, T. Asano, B. Vanhaesebroeck, and C. J. Watson. 2005. Stat3-induced apoptosis requires a molecular switch in PI(3)K subunit composition. Nat. Cell Biol. 7:392-398.

Accorsi, P. A., B. Pacioni, C. Pezzi, M. Forni, D. J. Flint, and E. Seren. 2002. Role of prolactin, growth hormone and insulin-like growth factor 1 in mammary gland involution in the dairy cow. J. Dairy Sci. 85:507-513.

Alexander, W. S., and D. J. Hilton. 2004. The role of suppressors of cytokine signaling (SOCS) proteins in regulation of the immune response. Annu. Rev. Immunol. 22:503-529.

Baxter, F. O., P. J. Came, K. Abell, B. Kedjouar, M. Huth, K. Rajewsky, M. Pasparakis, and C. J. Watson. 2006. IKKbeta/2 induces TWEAK and apoptosis in mammary epithelial cells. Development 133:3485-3494.

Baxter, F. O., K. Neoh, and M. C. Tevendale. 2007. The beginning of the end: Death signaling in early involution. J. Mammary Gland Biol. Neoplasia 12:3-13.

Bernier-Dodier, P., C. L. Girard, B. G. Talbot, and P. Lacasse. 2011. Effect of dry period management on mammary gland function and its endocrine regulation in dairy cows. J. Dairy Sci. 94:4922-4936.

Boutinaud, M., V. Lollivier, L. Finot, R. M. Bruckmaier, and P. Lacasse. 2012. Mammary cell activity and turnover in dairy cows treated with the prolactin-release inhibitor quinagolide and milked once daily. J. Dairy Sci. 95:177-187.

Boutinaud, M., J. H. Shand, M. A. Park, K. Phillips, J. Beattie, D. J. Flint, and G. J. Allan. 2004. A quantitative RT-PCR study of the mRNA expression profile of the IGF axis during mammary gland development. J. Mol. Endocrinol. 33:195-207.

Capuco, A. V., and R. M. Akers. 1999. Mammary involution in dairy animals. J. Mammary Gland Biol. Neoplasia 4:137-144.

Capuco, A. V., D. L. Wood, R. Baldwin, K. McLeod, and M. J. Paape. 2001. Mammary cell number, proliferation, and apoptosis during a bovine lactation: Relation to milk production and effect of bST. J. Dairy Sci. 84:2177-2187.

Chapman, R. S., P. C. Lourenco, E. Tonner, D. J. Flint, S. Selbert, K. Takeda, S. Akira, A. R. Clarke, and C. J. Watson. 1999. Suppression of epithelial apoptosis and delayed mammary gland involution in mice with a conditional knockout of Stat3. Genes Dev. $13: 2604-2616$

Clarkson, R. W., M. P. Boland, E. A. Kritikou, J. M. Lee, T. C. Freeman, P. G. Tiffen, and C. J. Watson. 2006. The genes induced by signal transducer and activators of transcription STAT3 and STAT5 in mammary epithelial cells define the roles of these STATs in mammary development. Mol. Endocrinol. 20:675-685.

Clarkson, R. W., J. L. Heeley, R. Chapman, F. Aillet, R. T. Hay, A. Wyllie, and C. J. Watson. 2000. NF-kappaB inhibits apoptosis in murine mammary epithelia. J. Biol. Chem. 275:12737-12742.

Clarkson, R. W., M. T. Wayland, J. Lee, T. Freeman, and C. J. Watson. 2004. Gene expression profiling of mammary gland development reveals putative roles for death receptors and immune mediators in post-lactational regression. Breast Cancer Res. 6:R92R109.

Croker, B. A., H. Kiu, and S. E. Nicholson. 2008. SOCS regulation of the JAK/STAT signaling pathway. Semin. Cell Dev. Biol. 19:414422 .
Cui, Y., G. Riedlinger, K. Miyoshi, W. Tang, C. Li, C. X. Deng, G. W. Robinson, and L. Hennighausen. 2004. Inactivation of Stat5 in mouse mammary epithelium during pregnancy reveals distinct functions in cell proliferation, survival, and differentiation. Mol. Cell. Biol. 24:8037-8047.

Dalley, D. E., and S. R. Davis. 2006. Effect of an extended milking interval on recovery of milk yield and somatic cell count in dairy cows. Proc. N.Z. Soc. Anim. Prod. 66:241-244.

Davey, R. E., K. Onishi, A. Mahdavi, and P. W. Zandstra. 2007. LIFmediated control of embryonic stem cell self-renewal emerges due to an autoregulatory loop. FASEB J. 21:2020-2032.

Davis, S. R., V. C. Farr, and K. Stelwagen. 1999. Regulation of yield loss and milk composition during once-daily milking: A review. Livest. Prod. Sci. 59:77-94.

Dif, F., E. Saunier, B. Demeneix, P. A. Kelly, and M. Edery. 2001. Cytokine-inducible SH2-containing protein suppresses PRL signaling by binding the PRL receptor. Endocrinology 142:5286-5293.

Edelstein-Keshet, L. 1988. Mathematical Models in Biology. 1st ed. Random House, New York, NY.

Flint, D. J., and C. H. Knight. 1997. Interactions of prolactin and growth hormone $(\mathrm{GH})$ in the regulation of mammary gland function and epithelial cell survival. J. Mammary Gland Biol. Neoplasia 2:41-48.

GenStat. 2011. GenStat for Windows 14th ed. GenStat.co.uk. VSN International. Hemel Hempstead, UK.

Gertler, A., J. Grosclaude, C. J. Strasburger, S. Nir, and J. Djiane. 1996. Real-time kinetic measurement of the interaction between lactogenic hormones and prolactin-receptor extracellular domains from several species support the model of hormone-induced transient receptor dimerization. J. Biol. Chem. 271:24482-24491.

Gilmore, A. P., A. D. Metcalfe, L. H. Romer, and C. H. Streuli. 2000. Integrin-mediated survival signals regulate the apoptotic function of Bax through its conformation and subcellular localization. J. Cell Biol. 149:431-446.

Granillo, A. R., J. C. Boffi, L. Barañao, E. Kordon, A. Pecci, and A. Guberman. 2007. STAT5 transcriptional activity is impaired by LIF in a mammary epithelial cell line. Biochem. Biophys. Res. Commun. 356:727-732.

Gunawardena, J. 2010. Models in systems biology: The parameter problem and the meanings of robustness. Pages 21-47 in Elements of Computational Systems Biology. H. M. Lodhi and S. H. Muggleton, ed. Wiley \& Sons Inc., Hoboken, NJ.

Harris, J., P. M. Stanford, K. Sutherland, S. R. Oakes, M. J. Naylor, F. G. Robertson, K. D. Blazek, M. Kazlauskas, H. N. Hilton, S. Wittlin, W. S. Alexander, G. J. Lindeman, J. E. Visvader, and C. J. Ormandy. 2006. Socs2 and Elf5 mediate prolactin-induced mammary gland development. Mol. Endocrinol. 20:1177-1187.

Holst, B. D., W. L. Hurley, and D. R. Nelson. 1987. Involution of the bovine mammary gland: Histological and ultrastructural changes. J. Dairy Sci. 70:935-944.

Hurley, W. L. 1989. Mammary gland function during involution. J. Dairy Sci. 72:1637-1646.

Iavnilovitch, E., B. Groner, and I. Barash. 2002. Overexpression and forced activation of Stat5 in mammary gland of transgenic mice promotes cellular proliferation, enhances differentiation, and delays postlactational apoptosis. Mol. Cancer Res. 1:32-47.

Jaggi, R., A. Marti, K. Guo, Z. Feng, and R. R. Friis. 1996. Regulation of a physiological apoptosis: mouse mammary involution. J. Dairy Sci. 79:1074-1084.

Kile, B. T., and W. S. Alexander. 2001. The suppressors of cytokine signaling (SOCS). Cell. Mol. Life Sci. 58:1627-1635.

Kretzschmar, A. K., M. C. Dinger, C. Henze, K. Brocke-Heidrich, and F. Horn. 2004. Analysis of Stat3 (signal transducer and activator of transcription 3) dimerization by fluorescence resonance energy transfer in living cells. Biochem. J. 377:289-297.

Kritikou, E. A., A. Sharkey, K. Abell, P. J. Came, E. Anderson, R. W. Clarkson, and C. J. Watson. 2003. A dual, non-redundant, role for LIF as a regulator of development and STAT3-mediated cell death in mammary gland. Development 130:3459-3468.

Li, M., X. Liu, G. Robinson, U. Bar-Peled, K. U. Wagner, W. S. Young, L. Hennighausen, and P. A. Furth. 1997. Mammary-derived signals 
activate programmed cell death during the first stage of mammary gland involution. Proc. Natl. Acad. Sci. USA 94:3425-3430.

Lindeman, G. J., S. Wittlin, H. Lada, M. J. Naylor, M. Santamaria, J. G. Zhang, R. Starr, D. J. Hilton, W. S. Alexander, C. J. Ormandy, and J. Visvader. 2001. SOCS1 deficiency results in accelerated mammary gland development and rescues lactation in prolactin receptor-deficient mice. Genes Dev. 15:1631-1636.

Liu, X., G. W. Robinson, F. Gouilleux, B. Groner, and L. Hennighausen. 1995. Cloning and expression of Stat5 and an additional homologue (Stat5b) involved in prolactin signal transduction in mouse mammary tissue. Proc. Natl. Acad. Sci. USA 92:8831-8835.

Liu, X., G. W. Robinson, and L. Hennighausen. 1996. Activation of Stat5a and Stat5b by tyrosine phosphorylation is tightly linked to mammary gland differentiation. Mol. Endocrinol. 10:1496-1506.

Lund, L. R., J. Romer, N. Thomasset, H. Solberg, C. Pyke, M. J. Bissell, K. Dano, and Z. Werb. 1996. Two distinct phases of apoptosis in mammary gland involution: proteinase-independent and -dependent pathways. Development 122:181-193.

Mallah, G. S., J. Dobson, S. Moon, H. V. Henderson, A. Molenaar, J. Guan, and K. Singh. 2013. The effect of re-milking following extended non-milkingperiods on the proliferation and apoptosis of mammary epithelial cells in dairy cows. Proc. N.Z. Soc. Anim. Prod. 73:51-53.

Maroulakou, I. G., W. Oemler, S. P. Naber, I. Klebba, C. Kuperwasser, and P. N. Tsichlis. 2008. Distinct roles of the three Akt isoforms in lactogenic differentiation and involution. J. Cell. Physiol. 217:468-477.

McMahon, C. D., V. C. Farr, K. Singh, T. T. Wheeler, and S. R. Davis. 2004. Decreased expression of beta1-integrin and focal adhesion kinase in epithelial cells may initiate involution of mammary glands. J. Cell Physiol. 200:318-325.

Murney, R., K. Stelwagen, T. T. Wheeler, J. K. Margerison, and K. Singh. 2015. Activation of signal transducer and activator of transcription 5 (STAT5) is linked to $\beta 1$-integrin protein abundance in unilaterally milked bovine mammary glands. J. Dairy Sci. 98:3133-3142.

Naka, T., M. Narazaki, M. Hirata, T. Matsumoto, S. Minamoto, A. Aono, N. Nishimoto, T. Kajita, T. Taga, K. Yoshizaki, S. Akira, and T. Kishimoto. 1997. Structure and function of a new STATinduced STAT inhibitor. Nature 387:924-929.

Nguyen, A. V., and J. W. Pollard. 2000. Transforming growth factor beta3 induces cell death during the first stage of mammary gland involution. Development 127:3107-3118.

Noble, M. S., and W. L. Hurley. 1999. Effects of secretion removal on bovine mammary gland function following an extended milk stasis. J. Dairy Sci. 82:1723-1730.

Philp, J. A., T. G. Burdon, and C. J. Watson. 1996. Differential activation of STATs 3 and 5 during mammary gland development. FEBS Lett. 396:77-80.

Quarrie, L. H., C. V. Addey, and C. J. Wilde. 1994. Local regulation of mammary apoptosis in the lactating goat. Biochem. Soc. Trans. $22: 178 \mathrm{~S}$.

Quarrie, L. H., C. V. Addey, and C. J. Wilde. 1996. Programmed cell death during mammary tissue involution induced by weaning, litter removal, and milk stasis. J. Cell. Physiol. 168:559-569.

Robinson, G. W., M. Pacher-Zavisin, B. M. Zhu, A. Yoshimura, and L. Hennighausen. 2007. Socs 3 modulates the activity of the transcription factor Stat3 in mammary tissue and controls alveolar homeostasis. Dev. Dyn. 236:654-661.

Schmitt-Ney, M., B. Happ, P. Hofer, N. E. Hynes, and B. Groner. 1992. Mammary gland-specific nuclear factor activity is positively regulated by lactogenic hormones and negatively by milk stasis. Mol. Endocrinol. 6:1988-1997.

Schorr, K., M. Li, S. Krajewski, J. C. Reed, and P. A. Furth. 1999. Bcl2 gene family and related proteins in mammary gland involution and breast cancer. J. Mammary Gland Biol. Neoplasia 4:153-164.

Schwertfeger, K. L., M. M. Richert, and S. M. Anderson. 2001. Mammary gland involution is delayed by activated Akt in transgenic mice. Mol. Endocrinol. 15:867-881.

Singh, K., S. R. Davis, J. M. Dobson, A. J. Molenaar, T. T. Wheeler, C. G. Prosser, V. C. Farr, K. Oden, K. M. Swanson, C. V. Phyn,
D. L. Hyndman, T. Wilson, H. V. Henderson, and K. Stelwagen. 2008. cDNA microarray analysis reveals that antioxidant and immune genes are upregulated during involution of the bovine mammary gland. J. Dairy Sci. 91:2236-2246.

Singh, K., J. Dobson, C. V. C. Phyn, S. R. Davis, V. C. Farr, A. J. Molenaar, and K. Stelwagen. 2005. Milk accumulation decreases expression of genes involved in cell-extracellular matrix communication and is associated with induction of apoptosis in the bovine mammary gland. Livest. Prod. Sci. 98:67-78.

Singh, K., K. M. Swanson, H. V. Henderson, R. A. Erdman, and K. Stelwagen. 2015. The effect of milking reinitiation following extended non-milking periods on lactation in primiparous dairy cows. J. Dairy Sci. 98:7666-7674.

Soboleva, T. K., I. Vetharaniam, A. J. Nixon, R. Montenegro, A. J. Pearson, and J. Sneyd. 2005. Mathematical modelling of prolactinreceptor interaction and the corollary for prolactin receptor gene expression in skin. J. Theor. Biol. 234:289-298.

Sorensen, M. T., J. V. Norgaard, P. K. Theil, M. Vestergaard, and K. Sejrsen. 2006. Cell turnover and activity in mammary tissue during lactation and the dry period in dairy cows. J. Dairy Sci. 89:4632-4639.

Sutherland, K. D., G. J. Lindeman, and J. E. Visvader. 2007. Knocking off SOCS genes in the mammary gland. Cell Cycle 6:799-803.

Sutherland, K. D., F. Vaillant, W. S. Alexander, T. M. Wintermantel, N. C. Forrest, S. L. Holroyd, E. J. McManus, G. Schutz, C. J. Watson, L. A. Chodosh, G. J. Lindeman, and J. E. Visvader. 2006. c-myc as a mediator of accelerated apoptosis and involution in mammary glands lacking Socs3. EMBO J. 25:5805-5815.

Tam, S. P., P. Lau, J. Djiane, D. J. Hilton, and M. J. Waters. 2001. Tissue-specific induction of SOCS gene expression by PRL. Endocrinology 142:5015-5026.

Tonko-Geymayer, S., O. Goupille, M. Tonko, C. Soratroi, A. Yoshimura, C. Streuli, A. Ziemiecki, R. Kofler, and W. Doppler. 2002. Regulation and function of the cytokine-inducible SH-2 domain proteins, CIS and SOCS3, in mammary epithelial cells. Mol. Endocrinol. 16:1680-1695.

Tonner, E., M. C. Barber, M. T. Travers, A. Logan, and D. J. Flint. 1997. Hormonal control of insulin-like growth factor-binding protein-5 production in the involuting mammary gland of the rat. Endocrinology 138:5101-5107.

Travers, M. T., M. C. Barber, E. Tonner, L. Quarrie, C. J. Wilde, and D. J. Flint. 1996. The role of prolactin and growth hormone in the regulation of casein gene expression and mammary cell survival: relationships to milk synthesis and secretion. Endocrinology 137:1530-1539.

van Riel, N. A. W. 2006. Dynamic modelling and analysis of biochemical networks: mechanism-based models and model-based experiments. Brief. Bioinform. 7:364-374.

Vetharaniam, I., S. R. Davis, T. K. Soboleva, P. R. Shorten, and G. C. Wake. 2003. Modeling the interaction of milking frequency and nutrition on mammary gland growth and lactation. J. Dairy Sci. 86:1987-1996.

Walker, N. I., R. E. Bennett, and J. F. Kerr. 1989. Cell death by apoptosis during involution of the lactating breast in mice and rats. Am. J. Anat. 185:19-32.

Walker, S. R., E. A. Nelson, L. Zou, M. Chaudhury, S. Signoretti, A. Richardson, and D. A. Frank. 2009. Reciprocal effects of STAT5 and STAT3 in breast cancer. Mol. Cancer Res. 7:966-976.

Wall, E. H., T. L. Auchtung, G. E. Dahl, S. E. Ellis, and T. B. McFadden. 2005. Exposure to short day photoperiod during the dry period enhances mammary growth in dairy cows. J. Dairy Sci. 88:1994-2003.

Wall, E. H., H. M. Crawford, S. E. Ellis, G. E. Dahl, and T. B. McFadden. 2006. Mammary response to exogenous prolactin or frequent milking during early lactation in dairy cows. J. Dairy Sci. 89:4640-4648

Wheeler, T. T., M. K. Broadhurst, H. B. Sadowski, V. C. Farr, and C. G. Prosser. 2001. Stat5 phosphorylation status and DNA-binding activity in the bovine and murine mammary glands. Mol. Cell. Endocrinol. 176:39-48. 
Wilde, C. J., C. Addey, P. Li, and D. Fernig. 1997. Programmed cell death in bovine mammary tissue during lactation and involution. Exp. Physiol. 82:943-953.

Wilde, C. J., C. H. Knight, and D. J. Flint. 1999. Control of milk secretion and apoptosis during mammary involution. J. Mammary Gland Biol. Neoplasia 4:129-136.

\section{APPENDIX}

The model consists of 2 sub-models (LIF and PRL) that are coupled via common variables. For completeness, delays are included in the differential equations. However, the timescale of the delays is much smaller than the timescale of the simulation period, and calculation assuming delays are zero did not significantly alter the dynamics. Delayed values of variables are indicated using the standard mathematical notation of writing the time minus the length of the delay in parentheses after the variable. For example, if we had a variable y and used its delayed values in an equation, this would be written in the equation as $\mathrm{y}(\mathrm{t}-\tau)$, where $\mathrm{t}$ is the independent time variable and $\tau$ is the lag time. If we set the delay to zero, this becomes $\mathrm{y}=\mathrm{y}(\mathrm{t})$.

\section{LIF Signaling Model}

The concentrations of the LIF receptor and the transmembrane receptor gp130 were denoted by $R_{L}$ and $G$, respectively (both $\mathrm{n} M$ ), and the concentrations of LIF, LIF-LIFR, and LIF-LIFR-gp130 (all $\mathrm{n} M$ ) by $L, L_{1}$, and $L_{2}$, respectively; $L$ is specified as an external input, whereas other variables have associated differential equations (DE):

$$
\frac{\mathrm{d} R_{L}}{\mathrm{~d} t}=\rho_{R L}-\delta_{R L} R_{L}-k_{L 1, f} L R_{L}+k_{L 1, b} L_{1},
$$

where $\rho_{R L}\left(\mathrm{n} M \mathrm{~min}^{-1}\right)$ is the rate of LIFR production, $\delta_{R L}\left(\mathrm{~min}^{-1}\right)$ is the rate of degradation or internalization of LIFR, and $k_{\mathrm{L} 1, f}\left(\mathrm{n} M^{-1} \mathrm{~min}^{-1}\right)$ and $k_{\mathrm{L} 1, b}\left(\mathrm{~min}^{-1}\right)$ are the binding and dissociation constants associated with LIF-LIFR;

$$
\frac{\mathrm{d} G}{\mathrm{~d} t}=\rho_{G}-\delta_{G} G-k_{L 2, f} G L_{1}+k_{L 2, b} L_{2},
$$

where $\rho_{G}\left(\mathrm{n} M \mathrm{~min}^{-1}\right)$ is the rate of gp130 production, $\delta_{G}\left(\mathrm{~min}^{-1}\right)$ is rate of degradation or internalization of gp130, and $k_{\mathrm{L} 2, f}\left(\mathrm{n} M^{-1} \min ^{-1}\right)$ and $k_{\mathrm{L} 2, b}\left(\min ^{-1}\right)$ are the association and dissociation constants of LIF-LIFR and gp130, respectively;

$$
\frac{\mathrm{d} L_{1}}{\mathrm{~d} t}=k_{L 1, f} L R_{L}-k_{L 1, b} L_{1}-k_{L 2, f} G L_{1}+k_{L 2, b} L_{2},
$$

where $k_{\mathrm{L} 1, f}\left(\mathrm{n} M^{-1} \min ^{-1}\right)$ and $k_{\mathrm{L} 1, b}\left(\mathrm{~min}^{-1}\right)$ are, respectively, the association and dissociation constants for LIF and LIFR;

$$
\begin{aligned}
\frac{\mathrm{d} L_{2}}{\mathrm{~d} t} & =k_{L 2, f} G L_{1}-k_{L 2, b} L_{2}-\delta_{L 2} L_{2}-\phi_{L, f} L_{2} \\
& +\phi_{L, b} L_{2}^{*}-k_{L C 3, f} C_{3} L_{2}+k_{L C 3, b} L_{C 3},
\end{aligned}
$$

where $\delta_{L 2}\left(\mathrm{~min}^{-1}\right)$ is the rate of degradation or internalization of the LIF receptor dimer, $\phi_{L, f}$ and $\phi_{L, b}$ are the phosphorylation (by JAK2) and dephosphorylation rates $\left(\mathrm{min}^{-1}\right)$ of LIF-LIFR-gp130, $L_{2}^{*}(\mathrm{n} M)$ represents phosphorylated LIF-LIFR-gp130, $C_{3}$ and $L_{C 3}$ (both $\mathrm{n} M$ ) are concentrations of SOCS3 and SOCS3-LIF-LIFR-gp130, the latter having association and dissociation constants of, respectively, $k_{L C 3, f}\left(\mathrm{n} M^{-1} \min ^{-1}\right)$ and $k_{L C 3, b}\left(\mathrm{~min}^{-1}\right)$.

These last 3 introduced variables have the following DE:

$$
\frac{\mathrm{d} L_{2}^{*}}{\mathrm{~d} t}=\phi_{L, f} L_{2}-\phi_{L, b} L_{2}^{*}-\delta_{L 2} L_{2}^{*}
$$

$$
\frac{\mathrm{d} L_{C 3}}{\mathrm{~d} t}=k_{L C 3, f} C_{3} L_{2}-k_{L C 3, b} L_{C 3}-u_{L C 3} L_{C 3},
$$

where $u_{L C 3}\left(\mathrm{~min}^{-1}\right)$ is the rate of degradation (along the ubiquitin pathway) of SOCS3-LIF-LIFR-gp130, and

$$
\begin{aligned}
\frac{\mathrm{d} C_{3}}{\mathrm{~d} t}= & \frac{\lambda_{C 3} M_{C 3}(t-\tau)}{1+\lambda_{C 3, M M} M_{C 3}(t-\tau)}-\delta_{C 3} C_{3}-k_{L C 3, f} C_{3} L_{2} \\
& +k_{L C 3, b} L_{C 3}-k_{P C 3, f} C_{3} P_{2}+k_{P C 3, b} P_{C 3},
\end{aligned}
$$

where $\lambda_{C 3}\left(\mathrm{~min}^{-1}\right)$ and $\lambda_{C 3, M M}\left(\mathrm{n} M^{-1}\right)$ govern the rate of translation of SOCS3 mRNA, $M_{C 3}$ is the level of SOCS3 mRNA $(\mathrm{n} M), \tau(\min )$ is the lag between initiation of translation and appearance of protein, and $\delta_{C 3}\left(\mathrm{~min}^{-1}\right)$ is the degradation rate of SOCS3. The variables $P_{2}$ and $P_{C 3}$ (both $\mathrm{n} M$ ) represent the unphosphorylated PRLreceptor dimer and SOCS3 bound to this dimer, with $k_{P C 3, f}\left(\mathrm{n} M^{-1} \min ^{-1}\right)$ and $k_{P C 3, b}\left(\mathrm{~min}^{-1}\right)$ being the related association and dissociation constants. Thus, the last 2 terms of the above equation provide a means to couple to the PRL model.

The SOCS3 mRNA is transcribed at a rate given by a time-lagged Michaelis-Menten (MM) function of phosphorylated STAT3 $\left(S_{3}^{*}\right.$ in $\left.\mathrm{n} M\right)$, which is controlled by the parameters $\chi_{C 3, S 3}\left(\mathrm{~min}^{-1}\right)$ and $\chi_{C 3, M M}\left(\mathrm{n} M^{-1}\right)$, and has a degradation rate of $\delta_{m C 3}\left(\mathrm{~min}^{-1}\right)$ : 


$$
\frac{\mathrm{d} M_{C 3}}{\mathrm{~d} t}=\frac{\chi_{C 3, S 3} S_{3}^{*}(t-\tau)}{1+\chi_{C 3, M M} S_{3}^{*}(t-\tau)}-\delta_{m C 3} M_{C 3} .
$$

The concentration of STAT3-P is given by

$$
\frac{\mathrm{d} S_{3}^{*}}{\mathrm{~d} t}=\phi_{S 3, f} S_{3} L_{2}^{*}-\phi_{S 3, b} S_{3}^{*}-\delta_{S 3}^{*} S_{3}^{*},
$$

where $\phi_{S 3, f}\left(\mathrm{n} M^{-1} \mathrm{~min}^{-1}\right)$ governs the rate at which STAT3 $\left(S_{3}, \mathrm{n} M\right)$ is phosphorylated, $\phi_{S 3, b}\left(\mathrm{~min}^{-1}\right)$ is the rate of dephosphorylation of STAT3 in the nucleus, and $\delta_{S 3}^{*}\left(\mathrm{~min}^{-1}\right)$ is the rate of STAT3-P degradation.

Translation of STAT3 is governed by a time-lagged MM function of STAT3 mRNA $\left(M_{S 3}, \mathrm{n} M\right)$ with parameters $\lambda_{S 3}\left(\mathrm{~min}^{-1}\right)$ and $\lambda_{S 3, M M}\left(\mathrm{n} M^{-1}\right)$ :

$$
\begin{aligned}
\frac{\mathrm{d} S_{3}}{\mathrm{~d} t}= & \frac{\lambda_{S 3} M_{S 3}(t-\tau)}{1+\lambda_{S 3, M M} M_{S 3}(t-\tau)}-\delta_{S 3} S_{3}-\phi_{S 3, f} S_{3} L_{2}^{*} \\
& +\phi_{S 3, b} S_{3}^{*}(t-\tau),
\end{aligned}
$$

where $\delta_{S 3}\left(\mathrm{~min}^{-1}\right)$ is the STAT3 degradation rate, and the time lag of $\tau$ in the last term reflects the time taken for STAT3-P dephosphorylated in the nucleus to return to the cytoplasm.

The STAT3 mRNA is assumed to be transcribed at a constant rate, $\chi_{S 3}\left(\mathrm{n} M \mathrm{~min}^{-1}\right)$, and has a degradation rate given by $\delta_{m S 3}\left(\min ^{-1}\right)$ :

$$
\frac{\mathrm{d} M_{S 3}}{\mathrm{~d} t}=\chi_{S 3}-\delta_{m S 3} M_{S 3} .
$$

\section{PRL Signaling Model}

Prolactin was denoted by $P$, which is a constant external input. The PRLR are denoted by $R_{P}$, and receptor monomers and dimers by $P_{1}$ and $P_{2}($ all in $\mathrm{n} M)$. The dynamics for these are given by

$\frac{\mathrm{d} R_{P}}{\mathrm{~d} t}=\rho_{R P}-\delta_{R P} R_{P}-k_{P 1, f} R_{P} P+k_{P 1, b} P_{1}-k_{P 2, f} P_{1} R_{P}+k_{P 2, b} P_{2}$,

$$
\begin{aligned}
\frac{\mathrm{d} P_{1}}{\mathrm{~d} t}= & k_{P 1, f} P R_{P}-k_{P 1, b} P_{1}-k_{P 2, f} P_{1} R_{P}+k_{P 2, b} P_{2}, \\
\frac{\mathrm{d} P_{2}}{\mathrm{~d} t} & =k_{P 2, f} P_{1} R_{P}-k_{P 2, b} P_{2}-k_{P C 3, f} C_{3} P_{2} \\
& +k_{P C 3, b} P_{C 3}-\phi_{P, f} P_{2}+\phi_{P, b} P_{2}^{*}-\delta_{P 2} P_{2},
\end{aligned}
$$

where $\rho_{R P}\left(\mathrm{n} M \min ^{-1}\right)$ and $\delta_{R P}$ are the production and degradation rates of PRLR, $k_{P 1, f}\left(\mathrm{n}^{-1} \mathrm{~min}^{-1}\right)$ and $k_{P 1, b}$ $\left(\mathrm{min}^{-1}\right)$ are the association and dissociation rates for PRL-PRLR, $k_{P 2, f}\left(\mathrm{n}^{-1} \mathrm{~min}^{-1}\right)$ and $k_{P 1, b}\left(\mathrm{~min}^{-1}\right)$ are the association and dissociation rates for PRL-PRLRPRLR; $\phi_{P, f}\left(\mathrm{~min}^{-1}\right)$ is the rate of phosphorylation of PRL-PRLR-PRLR by JAK2, to produce an activated PRLR dimer $P_{2}^{*}$, and $\phi_{P, b}(\min )$ is the rate at which the activated dimer is dephosphorylated, and $k_{P C 3, f}\left(\mathrm{n} M^{-1}\right.$ $\left.\min ^{-1}\right)$ and $k_{P C 3, b}\left(\mathrm{~min}^{-1}\right)$ are the association and dissociation constants for SOCS3-PRL-PRLR-PRLR. This latter complex is denoted by $P_{C 3}(\mathrm{n} M)$ and is degraded along the ubiquitin pathway at a rate $u_{P C 3}$ $\left(\min ^{-1}\right)$ :

$$
\frac{\mathrm{d} P_{C 3}}{\mathrm{~d} t}=k_{P C 3, f} C_{3} P_{2}-k_{P C 3, b} P_{C 3}-u_{P C 3} P_{C 3} .
$$

The activated PRLR dimer is degraded at a rate $\delta_{P 2}$ $\left(\mathrm{min}^{-1}\right)$ and is in equilibrium binding with SOCS2 $\left(C_{2}\right.$, $\mathrm{n} M)$ with association and dissociation constants of $k_{P C 2, f}\left(\mathrm{n} M^{-1} \min ^{-1}\right)$ and $k_{P C 2, b}\left(\min ^{-1}\right)$. The SOCS2bound PRL dimer is dephosphorylated and degraded along the ubiquitin pathway at a rate $u_{P C 2}\left(\mathrm{~min}^{-1}\right)$. Thus, $P_{2}^{*}$ and $P_{C 2}^{*}$ are have the following DE:

$$
\frac{\mathrm{d} P_{2}^{*}}{\mathrm{~d} t}=\phi_{P, f} P_{2}-\phi_{P, b} P_{2}^{*}-k_{P C 2, f} C_{2} P_{2}^{*}+k_{P C 2, b} P_{C 2}^{*}-\delta_{P 2} P_{2}^{*},
$$

$$
\frac{\mathrm{d} P_{C 2}^{*}}{\mathrm{~d} t}=k_{P C 2, f} C_{2} P_{2}^{*}-k_{P C 2, b} P_{C 2}^{*}-u_{P C 2} P_{C 2}^{*} .
$$

Translation of SOCS2 is governed by a time-lagged MM function of SOCS2 mRNA $\left(M_{C 2}\right)$ with parameters $\lambda_{C 2}\left(\mathrm{~min}^{-1}\right)$ and $\lambda_{C 2, M M}\left(\mathrm{n} M^{-1}\right)$ and is degraded at a rate $\delta_{C 2}\left(\min ^{-1}\right)$ :

$$
\begin{aligned}
\frac{\mathrm{d} C_{2}}{\mathrm{~d} t}= & \frac{\lambda_{C 2} M_{C 2}(t-\tau)}{1+\lambda_{C 2, M M} M_{C 2}(t-\tau)}-\delta_{C 2} C_{2} \\
& -k_{P C 2, f} C_{2} P_{2}^{*}+k_{P C 2, b} P_{C 2}^{*} .
\end{aligned}
$$

The SOCS2 mRNA is similarly transcribed at a rate given by a time-lagged $\mathrm{MM}$ function of activated STAT5 $\left(S_{5}^{*}, \mathrm{n} M\right)$ with parameters $\chi_{C 2, S 5}\left(\mathrm{~min}^{-1}\right)$ and $\chi_{C 2, M M}\left(\mathrm{n} M^{-1}\right)$, and has a degradation rate of $\delta_{m C 2}$ $\left(\min ^{-1}\right)$ :

$$
\frac{\mathrm{d} M_{C 2}}{\mathrm{~d} t}=\frac{\chi_{C 2, S 5} S_{5}^{*}(t-\tau)}{1+\chi_{C 2, M M} \times S_{5}^{*}(t-\tau)}-\delta_{m C 2} M_{C 2} .
$$


Activation of STAT5 $\left(S_{5}, \mathrm{n} M\right)$ is proportional to the activated PRLR dimer by $\phi_{S 5, f}\left(\mathrm{~min}^{-1}\right)$, and activated STAT5 is dephosphorylated in the nucleus at a rate $\phi_{S 5, b}\left(\mathrm{~min}^{-1}\right)$ and degraded at a rate of $\delta_{S 5}^{*}\left(\min ^{-1}\right)$ :

$$
\frac{\mathrm{d} S_{5}^{*}}{\mathrm{~d} t}=\phi_{S 5, f} S_{5} P_{2}^{*}-\phi_{S 5, b} S_{5}^{*}-\delta_{S 5}^{*} S_{5}^{*} .
$$

Translation of STAT5 follows MM kinetics and is a lagged function of STAT5 mRNA with parameters $\lambda_{S 5}$ $\left(\mathrm{min}^{-1}\right)$ and $\lambda_{S 5, M M}\left(\mathrm{n} M^{-1}\right)$. Degradation of STAT5 is at a rate $\delta_{S 5}\left(\mathrm{~min}^{-1}\right)$ and as with STAT3, a time delay is allowed for deactivated STAT5 to transit from the nucleus to the cytoplasm:

$$
\begin{aligned}
\frac{\mathrm{d} S_{5}}{\mathrm{~d} t}= & \frac{\lambda_{S 5} M_{S 5}(t-\tau)}{1+\lambda_{S 5, M M} M_{S 5}(t-\tau)}-\delta_{S 5} S_{5} \\
& -\phi_{S 5, f} S_{5} P_{2}^{*}+\phi_{S 5, b} S_{5}^{*}(t-\tau) .
\end{aligned}
$$

Finally, STAT5 mRNA is governed by the following DE:

$$
\frac{\mathrm{d} M_{S 5}}{\mathrm{~d} t}=\chi_{S 5}+\frac{\chi_{S 5, S 5} S_{5}^{*}(t-\tau)}{1+\chi_{S 5, M M} S_{5}^{*}(t-\tau)}-\delta_{m S 5} M_{S 5},
$$

where $\chi_{S 5}\left(\mathrm{n} M \min ^{-1}\right)$ is a basal level of transcription, $\chi_{S 5, S 5}\left(\mathrm{~min}^{-1}\right)$ and $\chi_{S 5, M M}\left(\mathrm{n} M^{-1}\right)$ are MM parameters, and $\delta_{m S 5}\left(\mathrm{~min}^{-1}\right)$ is a degradation rate. 